\title{
Legenda aurea latina, elementos apócrifos y tradición catalana
}

\author{
Maria Carmen Puche López
}

Universitat d'Alacant

carmen.puche@ua.es

https://orcid.org/OOOO-OOO2-8308-7I69

Received: $02 / \mathrm{IO} / 2 \mathrm{O} 2 \mathrm{O}$; accepted $\mathrm{O} 2 / \mathrm{II} / 2 \mathrm{O} 2 \mathrm{O}$

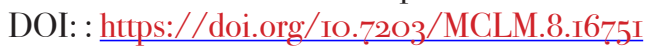

\section{Latin Legenda aurea, apocryphal elements and their Catalan tradition}

\begin{abstract}
A study on Iacobus de Voragine's warnings and observations about the apocryphal nature of some narrative elements within his Golden Legend. According to G. P. Maggioni's theory, most of these observations were inserted by Voragine in his second redaction of the work (LA2), and here we analyse to what extent and in what ways they are cited in the Legenda Aurea's Catalan tradition, taking as the study's basis the most recent edition of the Latin text (Maggion 2007) and four of the most important manuscripts of the Catalan tradition. We aim to provide new data about the textual history of the Catalan Golden Legend and its Latin model; and also, to find out to what extent the Catalan tradition was concerned with pinpointing its apocryphal material for the audience's benefit.
\end{abstract}

\section{KeYwords}

Hagiography; apocryphal; Legenda Aurea; Iacobus de Voragine; Medieval Latin Literature; Medieval Catalan Literature; Catalan Hagiography; Latin Hagiography

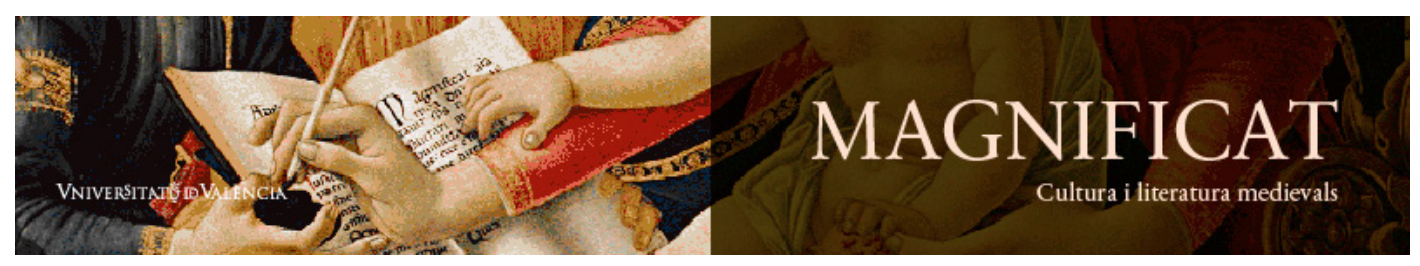

Magnificat Cultura i Literatura Medievals 8, 202I, 20I-227.
http://ojs.uv.es/index.php/MCLM

ISSN 2386-8295 
RESUMEN

Estudio de las advertencias que introduce Jacobo de la Vorágine sobre la naturaleza apócrifa de algunas leyendas o ciertos elementos narrativos que incluye en su Legenda aurea. Partiendo de la teoría de G. P. Maggioni de que la mayor parte de estas advertencias fueron introducidas por el dominico en su segunda redacción de la obra (LA2), analizamos en qué medida y de qué manera son recogidas en la tradición catalana de la obra, y tomamos como base para nuestro trabajo la edición más reciente del texto latino (Maggioni 2007), y cuatro de los manuscritos más importantes de la tradición catalana. Con este estudio comparativo pretendemos aportar nuevos datos a la historia textual de la Legenda aurea catalana en relación con su posible modelo latino y comprobar en qué medida hay en ella preocupación por delimitar claramente lo ‘apócrifo’ de cara al público al que va dirigida.

PALABRAS CLAVE

Hagiografía; apócrifo; Legenda Aurea; Iacobus de Voragine; literatura latina medieval; literatura catalana medieval; hagiografía catalana; hagiografía latina

Maria Carmen Puche. 202I. 'Legenda aurea latina, elementos apócrifos y tradición catalana', MagnificatCulturaiLiteraturaMedievals, 8:2OI-227,DOI:https://doi.org/IO.7203/MCLM.8.I675I $(\mathrm{coc}) \mathrm{Br}$

Este trabajo se inscribe en el marco del proyecto de investigación FFI2OI7-83950-P del Ministerio español de Ciencia, Innovación y Universidades.

\section{TABLA DE CONTENIDOS}

I Planteamiento, objetivos y metodología - 203

2 El término apocryphus en $L A$ : texto latino y tradición catalana - 205

2.I V De sancto Thoma apostolo, $\$ \$ 33-46-205$

2.2 XLV De sancto Mathia apostolo, $\$ \$ 13-14 ; 51-52-207$

2.3 LIDe passione Domini, \$\$183-185; 256-257 - 208

2.4 LVIDe sancto Georgio, $\$ \$ 12-17$ - 210

2.5 LXIII De sancto Iacobo apostolo, $\$ \$ 93 ; 143 ; 156$ - 2II

2. 6 LXIV De inuentione sanctae crucis, $\$ \$ 8 ; 11-2 \mathrm{I} 3$

2.7 LXXXIV De sancto Petro apostolo, \$\$212; 224; 243 - 2I4

2.8 LXXXIX De sancta Margarita, $\$ \$ 32-35$ - 2I5

2.9 CXV De assumptione beatae uirginis Mariae, $\$ \$ 1 ; 126-130-217$

2.IO CLXVIDe sancto Clemente, $\$ \$ 15^{2-157}-218$

3 Reflexiones sobre los datos: la actitud ante lo apócrifo en la tradición catalana - 220

3.I Coincidencias de los manuscritos catalanes con Vlat y con Elat $\left(=L A_{1}\right)-220$

3.2 Coincidencias de los manuscritos catalanes con Vlat, pero no con Elat - 22I

$3 \cdot 3$ Discrepancias de los manuscritos catalanes con Vlat y Elat - 222

4 Obras citadas -224 


\section{ə*⿻丷木}

\section{Planteamiento, objetivos y metodología}

E lestudio de la tradición catalana de la Legenda aurea desde una perspectiva comparatista, analizando las relaciones entre texto latino y texto catalán, permite plantear cuestiones como, por ejemplo, en qué medida podemos hablar de 'elementos originales' en la tradición catalana en relación con su modelo latino o si, dentro de las diferencias que presentan entre sí los manuscritos catalanes, unos resultan ser más fieles a la tradición latina que otros.

Desde esta aproximación metodológica, ${ }^{\mathrm{I}}$ queremos abordar aquí el estudio de un aspecto que consideramos especialmente relevante y significativo: cómo son recogidas en la tradición catalana de la Legenda aurea las menciones del término apocryphus que, a lo largo de su obra, hace Vorágine para calificar determinados elementos o leyendas que incluye en su legendario y, a la vez, advertir sobre ellos.

En relación con la obra latina, esta cuestión ha sido ya tratada por R. Gounelle (I994) quien analiza la presencia y significado de este término en la Legenda aurea en un interesante estudio. Por otro lado, después de él, G. P. Maggioni, que es el editor más reciente de la obra, ha desarrollado en diversos trabajos (I995c; ed. I998; 200I; 2008b) una teoría según la cual la mayor parte de estas advertencias sobre lo apócrifo son añadidas por Vorágine cuando su obra, ya en la segunda redacción $(L A 2)$, va dirigida no solo a los predicadores, sino también al público de los mismos. Es por ello por lo que el dominico considera necesarias mayores cautelas sobre cómo ha de ser utilizado ese material y, aunque no renuncia a incluirlo en su obra, advierte sobre la prudencia con que debe ser manejado. ${ }^{2}$

Estas conclusiones de Maggioni constituyen el punto de partida de nuestro trabajo. Ya que las advertencias sobre 'lo apócrifo' son, dentro de la tradición latina de $L A$, un elemento inestable y, a la vez, muy significativo en tanto que refleja el proceso de reelaboración de la obra, en este trabajo queremos comprobar si pueden aportar también nueva información en relación con la historia textual de la tradición catalana de la obra: ¿cómo son recogidas estas menciones sobre 'lo apócrifo' en la tradición catalana? ¿Hay discrepancias a este respecto entre el texto latino y el texto catalán? Lo que proponemos es, tomando como punto de partida la teoría de Maggioni, comprobar si podemos vincular el posible modelo latino de la tradición catalana con la tradición de $L A 1$ o con la de $L A 2$ en función de la presencia y tratamiento que reciben estas advertencias. ${ }^{3}$ Nuestro punto de referencia será el texto de su edición (I998 y 2007), en la que el estudioso italiano intenta reconstruir el estadio más avanzado y la última redacción que hizo Vorágine de la obra $(L A 2)$, y ofrece, en un aparato crítico paralelo, las variantes de los manuscritos que considera más representativos de la primera versión de la obra $(L A \imath) .{ }^{4}$

I. Que ya hemos aplicado en trabajos anteriores sobre la figura de María Magdalena (Puche 20I2) o la leyenda de Judas (Puche 20I8).

2. Sobre $L A$ y $L A 2$ y el complejísimo proceso de composición de la Legenda aurea, tanto por el número de manuscritos como por los diferentes estadios de redacción que la obra conoció, vid. Maggioni r995a; r995b; 200I; $2008 \mathrm{a}$.

3. Evidentemente, el planteamiento de este objetivo presupone la fidelidad de la traducción a su modelo latino, y no contempla, en principio, una intervención consciente del redactor catalán sobre el texto latino que recoge.

4. De acuerdo con su estudio (ed. I998: XIV ss.), la primera versión de la obra, $L A$, está representada sobre todo por los manuscritos $V=$ Padova, Biblioteca Universitaria, ms. I229 (s. XIII); $E=$ Milano, Biblioteca Ambrosiana, A I7 inf. (s. XIII), que aquí denominamos Vlat y Elat para no confundirlos con los catalanes que a continuación mencionaremos. 
Por otro lado, en lo que respecta a la tradición catalana, ésta aún no cuenta con una edición crítica propiamente dicha, y tiene diversos manuscritos representativos cuyas relaciones están aún en estudio desde la edición de Coromines (i977) del manuscrito Py la edición de Rebull (I976) del manuscrito $V$. Por ello, en nuestra comparación con el texto latino, vamos a trabajar sobre el texto de cuatro manuscritos que Garcia Sempere (2015: I6o ss.) identifica como principales dentro la tradición catalana. ${ }^{5}$ Son los siguientes:

- Manuscrito $P$ (ms. esp. 44 de BNF). Finales del s. XIII o principios del s. XIV. Editado por J.

Coromines en 1977 .

- Manuscrito $B$ (Bibl. Univ. Barcelona, 7I3). Finales del s. XIV o principios del s. XV.

- Manuscrito $E$ (N-III-5 del Escorial). Mediados del s. XIV. ${ }^{6}$

- Manuscrito V(s. c. I74 L del Arxiu Capitular de Vic). S. xv. Editado por N. Rebull en 1976.

El análisis nos permitirá también sacar conclusiones sobre las relaciones que mantienen entre sí los cuatro manuscritos: ¿se da el caso de que esas advertencias estén recogidas en algunos manuscritos y en otros no? ¿Podríamos decir que unos aplican un 'filtro' más estricto y conservador en relación con el material apócrifo que otros? Estas cuestiones tienen que ver con la difusión y recepción de la Legenda aurea en un ámbito catalán y con el estatus de legitimidad que se otorga a esos elementos apócrifos en la tradición catalana (una de las más tempranas en el largo camino que la Legenda aurea latina recorrió en el ámbito vernáculo) per se, al margen del modelo latino del que pueda derivar. ${ }^{7}$

En el apartado 2 recogemos todos los pasajes de la Legenda aurea en los que Vorágine utiliza el término apocryphus, que pertenecen a un total de diez capítulos. ${ }^{8}$ Tomamos el capítulo como unidad organizadora del apartado y, como veremos, en algunos hay una sola mención del término, mientras que en otros aparecen varias menciones.

La explicación y contextualización de cada pasaje en su leyenda correspondiente nos permitirán obtener una visión global de la tipología tan distinta de elementos apócrifos sobre los que Vorágine introduce esos juicios y advertencias. Después de la cita del texto latino, ofrecemos el pasaje correspondiente de los manuscritos catalanes y señalamos las coincidencias o discrepancias, según cada caso.

En el apartado 3 reflexionamos sobre los datos obtenidos y ofrecemos las conclusiones a las que llegamos en nuestro estudio, con el que, como decíamos anteriormente, pretendemos aportar algunos nuevos elementos de reflexión en relación con la historia textual y la recepción de la tradición catalana de la Legenda aurea.

5. Recogemos también la cronología que establece para cada manuscrito. Sobre la tradición catalana de la Legenda aurea, vid. Elizondo ı9ıо; Brunel ı976; Rebull ed. ı976: XVIII-LXIII; Brunel ı986; Tausend ı995; Wittlin 2003; Zinelli 2009; Avenoza-Garcia Sempere 2OI2; Garcia Sempere 2OI2; Garcia Sempere 2OI5.

6. Dentro del proyecto de investigación en el que se inscribe este trabajo, está en preparación una edición de este manuscrito, bajo la dirección de la Dra. Marinela Garcia Sempere.

7. Vid. Coromines I977: XII. Sobre la difusión e importancia de la Legenda aurea latina vid. Dunn-Lardeau I986; Fleith I99o; Fleith I99ז; Boureau 2004; Le Goff 2OII; Maggioni 20I2. Sobre diferentes tipos de audiencia de los relatos hagiográficos, vid. Rousselle I983: 27 ss.; Mackley 2008: I7 ss.

8. Incluimos también el capítulo LVI Desancto Georgio, donde hay una mención del término que no hemos encontrado en los estudios de Gounelle (1994) y Maggioni (2008b). 


\section{${ }_{2}$ El término apocryphus en $L A$ : texto latino y tradición catalana}

$\mathrm{L}$ as menciones del término apocryphus en la Legenda aurea, que son más bien escasas como ya señalaba Gounelle (ı994: 200), aparecen en leyendas de muy distintos tipos. El elemento etiquetado como apócrifo (o tomado de una fuente así calificada) puede ser también muy diverso en extensión y naturaleza: desde el origen no confirmado de un objeto sagrado (en De inuentione sanctae crucis) a leyendas enteras sobre enemigos del cristianismo como Judas (en De sancto Mathia) o Pilatos (en De passione Domini); desde un episodio novelesco y maravilloso, que se entiende como falso, en la vida de una figura de santidad (por ejemplo, el dragón que engulle a la santa en De sancta Margarita), a un episodio que parece poner en tela de juicio el comportamiento de apóstoles como Pedro (cuando parece incitar a mentir en De sancto Clemente) o Tomás (cuando parece querer cobrarse venganza de quien le ha ultrajado en De sancto Thoma).

Más allá de los matices y acepciones del término, para los que remitimos a los estudios ya mencionados de Gounelle (I994) y Maggioni (2008b), ${ }^{9}$ recogemos a continuación, de acuerdo con el objetivo de trabajo que hemos propuesto, los pasajes en que se contienen las apariciones del término para compararlos con los correspondientes en la tradición catalana.

\section{I V De sancto Thoma apostolo, $\$ \$ 33-46$}

La primera mención del término la encontramos en el capítulo de la vida del apóstol Tomás (§ 33-46). Invitado al banquete de un rey que celebraba la boda de su hija, y golpeado por el copero del banquete porque el apóstol no comía ni bebía y solo miraba al cielo, atento al canto de una muchacha, el santo anuncia que no se levantaría de su asiento hasta que los perros le trajeran la mano que le había golpeado, y así ocurre: el copero va a la fuente a por agua, es atacado por un león, que lo mata, y luego los perros destrozan su cadáver y uno de ellos se presenta en el banquete con la mano en la boca. Todos se quedan atónitos y la muchacha que cantaba se postra a sus pies.

Tras narrar el episodio, Vorágine aduce a continuación el juicio de San Agustín, el cual considera que esa actitud vengativa es impropia del apóstol y afirma que la anécdota es falsa. Pero el dominico, como explica Gounelle (I994: 204-O5), trata de matizar la afirmación para legitimar su inclusión en la leyenda y explica, utilizando palabras y argumentos del propio San Agustín en un largo pasaje que inserta a continuación, que una leyenda puede no haber sido recogida por fuentes canónicas y, aún así, tener valor moral intrínseco para ser utilizada en la predicación:

$L A \S 33-46$ : Huiusmodi autem ultionem factam reprobrat Augustinus in libro contra Faustum et asserit a pseudo hoc fuisse insertum, unde et legenda hec quo ad plura suspecta habetur. 34 Posset tamen dici quod hoc non animo impetrandi, sed modo predicendi dictum sit. 35 Si tamen Augustini uerba diligenter inspiciantur, non penitus ista reprobare uidetur; 36 ait enim sic in eodem libro: $37^{\circ}$ Legunt scripturas apocryphas Manichei a nescio quibus sutoribus fabularum sub apostolorum nomine scriptas que suorum scriptorum temporibus in auctoritate sancte ecclesie recipi mererentur, si sancti et docti homines qui tunc in hac uita erant et examinare illa poterant, eos uera locutos esse cognoscerent. 38Ibi tamen legunt apostolum Thomam, cum esset in quodam nuptiarum conuiuio peregrinus et prorsus incognitus a quodam ministro palma percussum imprecatum fuisse homini continuam seuamque uindictam. 39 Nam cum egressus esset ad fontem unde aquam conuiuantibus ministraret, in eum leo irruens interemit manumque eius, qua caput apostoli leui ictu percusserat, a

9. Sobre el concepto de 'apócrifo' en Vorágine relacionado con el tratamiento de la materia apócrifa en el flos sanctorum castellano, vid. Baños $202 \mathrm{O}$. 
corpore auulsam secundum uerbum eius apostoli id optantis atque imprecantis canis intulit mensis in quibus ipse discumbebat apostolus. 40Quid hoc uideri crudelius potest? $4 \mathrm{IV}$ Verum quia ibi, nisi fallor, hoc etiam scriptum est, quod ei ueniam in seculo futuro petierit, facta est compensatio beneficii maioris ut et apostolus quam carus deo esset per hunc timorem commendaretur ignotis et illi, post hanc uitam quandoque finiendam, in eternum consuleretur. ${ }_{42}$ Vtrum illa uera sit an conficta narratio, nihil mea nunc interest. 43 Certe enim Manichei a quibus ille scripture quas canon ecclesiasticus respuit tamquam uere ac sincere acceptantur saltem hic coguntur fateri, uirtutem illam patientie quam docet dominus dicens 'Si quis te percusserit in maxillam tuam dextram, prebe illi et sinistram' posse esse in preparatione cordis etiamsi non exhibeatur gestu corporis et expressione uerborum, quando quidem apostolus palma percussus potius deum rogauit ut iniurioso homini in futuro seculo parceretur, in presenti autem illa iniuria non inulta relinqueretur quam uel prebuit ferienti alteram partem aut ut iterum feriret admonuit. 44Tenebat certe interius dilectionis affectum et exterius requirebat correctionis exemplum. 45 Siue hoc uerum sit siue confictum, cur nolunt credere tali animo famulum dei Moysen ydoli fabricatores et adoratores gladio prostrauisse? ${ }_{4} 6 \mathrm{Si}$ autem penas illas comparamus, quid simile ferro interimi et a feris trucidari atque laniari, quando quidem iudices publicis legibus seruientes maioris criminis reos bestiis subrigi quam gladio percuti iubent?'. Hec Augustinus. ${ }_{47}$ Tunc apostolus ad petitionem regis sponsum et sponsam benedixit...

Toda esa reflexión ( $§ 33-46)$ aparece en la edición de Maggioni que, como decíamos anteriormente, reconstruye la versión más reciente que denomina $L A 2$, pero, sin embargo, falta en los manuscritos Vlat y Elat que son los representantes de $L A t^{\text {10 }}$

Si vemos qué recogen los manuscritos catalanes, la primera observación es que la vida de Santo Tomás se conserva en tres de los cuatro manuscritos $(E P B)$, mientras que por una laguna falta en el manuscrito $V$."

Los tres manuscritos recogen el episodio, pero omiten toda la reflexión sobre su legimitidad, de modo que, después de explicar la reacción de la joven que se arroja a los pies del apóstol, prosiguen con la narración de cómo el santo bendijo a los nuevos esposos en la celebración de cuyas nupcias tienen lugar los hechos que acabamos de narrar:

\begin{tabular}{|c|c|c|c|c|}
\hline$L A$ & $E$ (f. I4V) & $V$ & $P$ (f. I4 4 ) & $B$ (f. I3v) \\
\hline $\begin{array}{l}32 \text { Quo uiso omnis } \\
\text { turba obstupuit et } \\
\text { puella eius uerba } \\
\text { referens proiecta } \\
\text { fistula ad pedes } \\
\text { apostoli se proiecit. } \\
\text { [§§ } 33-46] \\
47 \text { Tunc apostolus } \\
\text { ad petitionem regis } \\
\text { sponsum et sponsam } \\
\text { benedixit }\end{array}$ & $\begin{array}{l}\text { Per què foren tots } \\
\text { maraveylats quant } \\
\text { ho viren. } \\
\text { E dementre que la } \\
\text { punçela les paraules } \\
\text { de sent Thomàs lus } \\
\text { recontave, gità la } \\
\text { caramela e mes-se } \\
\text { als peus de l'apòstol. } \\
\text { E sent Thomàs, } \\
\text { per prechs del } \\
\text { rrey, preguà nostre } \\
\text { Senyor Déus } \\
\text { per l'espòs e per } \\
\text { l'espose dient }\end{array}$ & - & $\begin{array}{l}\text { Per la qual cosa totz } \\
\text { quantz n'ac en la cort, } \\
\text { foren mout maravelatz } \\
\text { quant o veseren. E } \\
\text { dementre que la pun- } \\
\text { cela les paraules de } \\
\text { sent Tomàs recomtava, } \\
\text { gitada la caramela, } \\
\text { als peus de l' apòstol } \\
\text { humilment se gità. } \\
\text { E aprés aqueles } \\
\text { coses que dites } \\
\text { són, l'apòstol, per } \\
\text { pregueres del rey, lo } \\
\text { seu fil, qui era espòs, } \\
\text { e la sua esposa beneý, } \\
\text { dién }\end{array}$ & $\begin{array}{l}\text { Per la qual causa tots } \\
\text { quants n'ach a la cort, } \\
\text { foren molts maravellats } \\
\text { quant ho veseren. E } \\
\text { dementre que la puncella } \\
\text { les paraules recomtava } \\
\text { de sent Thomas, gitada } \\
\text { la caramella, als peus de } \\
\text { l'apòstol humilment se gità. } \\
\text { E aprés de aquellas coses } \\
\text { que dites són, l'apòstoll, } \\
\text { per pregueres del rey, lo } \\
\text { seu fil, qui era espòs, e la } \\
\text { sua esposa benesí, dient }\end{array}$ \\
\hline
\end{tabular}

IO. Vid. supra, notas 2 y 4 .

II. El editor la incluye en un apéndice a partir del manuscrito $B$ (Rebull ed. ı976: XXXVIII). 
Así pues, de acuerdo con el testimonio de este pasaje, la tradición catalana parece seguir un modelo vinculado a la tradición de $L A$, porque en la omisión de toda la reflexión sobre la naturaleza 'apócrifa' del episodio coincide con los manuscritos latinos elegidos por Maggioni como representantes más genuinos de esta tradición (Vlat y Elat).

\subsection{De sancto Mathia apostolo, $\$ \$ 13-14 ; 5^{1-52}$}

En la vida del apóstol Matías se incluye la leyenda de Judas, que es particularmente interesante y, al igual que otras tres a las que iremos aludiendo en su lugar, está tomada, según afirma explícitamente Vorágine, de una Hystoria apocrypha.$^{\text {.2 }}$ Como ya hemos señalado en otro lugar (Puche 2OI8: 2I4I5), el dominico se permite incluir, a propósito de la vida del apóstol que ocupó el lugar de Judas, esta leyenda edípica sobre uno de los personajes malditos del cristianismo y, tras narrarla, introduce la advertencia sobre si es o no conveniente leerla ante una audiencia. Lo interesante es que aprovecha la leyenda del apóstol Matías para, por un momento, desplazar el foco de atención hacia la figura de Judas, un personaje 'elegido para el mal', familiarizado con los crímenes desde su infancia y, por ello mismo, particularmente atractivo y novelesco. Vorágine se permite contar su historia, pero delimitando claramente su comienzo y su final con esa etiqueta de 'apócrifa':

$L A \S \S$ I3-I 4 : Mathias apostolus in locum Iude proditoris substitutus est, sed primo ortum et originem ipsius Iude breuiter uideamus. I4Legitur enim in quadam hystoria licet apocrypha quod fuit quidam uir in Iherusalem nomine Ruben, qui alio nomine dictus est Symon, de tribu Iuda, uel secundum Ieronimum de tribu Ysachar, qui habuit uxorem que Cyborea nuncupata est.

$[\ldots]$

$L A \S \S 5^{\mathrm{I}-} 5^{2:}$ Hucusque in predicta hystoria apocrypha legitur; $5^{2 q u e}$ utrum recitanda sit, lectoris arbitrio relinquatur, licet sit potius relinquenda quam asserenda.

De las dos menciones del término, la primera (§ I4) aparece en Vlat y Elat, mientras que la segunda $\left(\$ \S 5^{\mathrm{I}-} 5^{2}\right)$, con la advertencia sobre las cautelas necesarias en su utilización, no aparece en ninguno de los dos. De hecho, este es uno de los pasajes sobre los que Maggioni (I995c; 20o8: I73-74) sustenta su teoría de que estas advertencias, relacionadas con la fuente de la que se sirvió Vorágine, fueron introducidas en su segunda versión de la obra.

En los manuscritos catalanes, comprobamos que la vida del apóstol Matías está en los cuatro manuscritos; la leyenda de Judas también, así como la mención de la fuente. En lo que respecta a las menciones del término apocrypha, la primera de ellas está en tres manuscritos, $V P B$, que lo traducen como "ystòria qui no és creseguda". El manuscrito $E$, en cambio, no recoge el adjetivo y solo habla de una "ystoria”. Esta omisión es una singularidad de este manuscrito, que interpretamos más bien como un descuido u olvido por parte de este redactor, ${ }^{13}$ pero sin consecuencias significativas para nuestro objetivo de intentar una 'filiación' textual del posible modelo latino de la traducción catalana.

I2. Vid. Steinmeyer I9ı8; Gaiffier ı973; Maggioni ı995c; Maggioni I998.

I3. Este manuscrito presenta algunas lecturas peculiares que lo diferencian de los demás, como hemos constatado en el caso de la leyenda de Pilatos (vid. Albert-Puche 2019 y el apartado 2.3 de este trabajo). Además, veremos que son varios los casos (vid. infra los apartados 2.4, 2.5 y 2.6) en que no recoge una leyenda o pasaje que sí aparece en los otros tres manuscritos $(V P B)$. 
Por otro lado, la segunda mención del término apocrypha, que aparece marcando el final de la leyenda juntamente con la advertencia sobre su recitación, está ausente en todos los manuscritos catalanes:

\begin{tabular}{|c|c|c|c|c|}
\hline$L A$ & $E$ (f. $59 \mathrm{v})$ & $V($ f. $15 \mathrm{v})$ & $P$ (f. zor) & $B$ (f. 82r) \\
\hline $\begin{array}{l}\text { I3Mathias } \\
\text { apostolus in locum } \\
\text { Iude proditoris } \\
\text { substitutus } \\
\text { est, sed primo } \\
\text { ortum et originem } \\
\text { ipsius Iude breuiter } \\
\text { uideamus. I4 Legitur } \\
\text { enim in quadam } \\
\text { hystoria licet } \\
\text { apocrypha quod... }\end{array}$ & $\begin{array}{l}\text { Machia apòstol fo } \\
\text { establit e posat en loch } \\
\text { d'en Judes, per què } \\
\text { primerament vejam } \\
\text { lo comensament e.l } \\
\text { neximent del trahidor } \\
\text { breument. És legit en } \\
\text { una ystoria que... }\end{array}$ & $\begin{array}{l}\text { Mathia apòstol fo } \\
\text { establit e posat en } \\
\text { loch d'en Judes } \\
\text { Escariot. Per què } \\
\text { primerament vejam } \\
\text { lo comensament e.l } \\
\text { naximent del traydor } \\
\text { breument. És legit } \\
\text { en una istòria que } \\
\text { no és creeguda que... }\end{array}$ & $\begin{array}{l}\text { Matià apòstol fo } \\
\text { establit e posat } \\
\text { en lo loc de } \\
\text { Judes. Per què, } \\
\text { primerament } \\
\text { veyam lo nexament } \\
\text { e.l comensament } \\
\text { del traytor. } \\
\text { Breument és lest } \\
\text { en una ystòria qui } \\
\text { no és creseguda, } \\
\text { qui-s vol, que... }\end{array}$ & $\begin{array}{l}\text { Macià apòstol fo } \\
\text { stablit e pausat en } \\
\text { loch de Judes. Per què, } \\
\text { primerament veyam lo } \\
\text { nexament de Judes. En } \\
\text { lo comensament del } \\
\text { traydor breument és lest } \\
\text { en una ystòria qui no } \\
\text { és creseguda, qui·s vol, } \\
\text { que... }\end{array}$ \\
\hline $\begin{array}{l}\text { 5 }{ }^{\text {Hucusque in }} \\
\text { predicta hystoria } \\
\text { apocrypha legitur; } \\
\text { 52que utrum } \\
\text { recitanda sit, lectoris } \\
\text { arbitrio relinquatur, } \\
\text { licet sit potius } \\
\text { relinquenda quam } \\
\text { asserenda. }\end{array}$ & & & & \\
\hline
\end{tabular}

Dado que la primera mención aparece en los manuscritos Vlat y Elat, correspondientes a $L A 1$, y la segunda mención con la advertencia final no, podríamos decir que el testimonio de este pasaje, al igual que el anterior, permite mantener la hipótesis de que el modelo latino podría pertenecer a la tradición de $L A$.

\subsection{De passione Domini, \$\$ 183-185; 256-257}

En el capítulo dedicado a la pasión de Cristo, Vorágine actúa de la misma manera que en el capítulo dedicado al apóstol Matías: se permite incluir otra leyenda tomada de la misma fuente, esa Hystoria apocrypha que ya hemos mencionado, que en este caso gira en torno a otro 'malvado' del cristianismo: Pilatos, el gobernador que entregó a Jesús a la muerte.

Como ya hemos dicho en otro lugar (Puche 20I9), la leyenda narra el antes y el después de la actuación de Pilatos como gobernador y funciona como exemplum a contrario, reproduciendo en antitética simetría situaciones y tópicos propios de las passiones. En este caso, pues, el elemento etiquetado como apócrifo es toda una leyenda que, sin duda, haría las delicias del público al conocer cómo se ejecuta la condena de un personaje cuya maldad excede los límites naturales de la condición humana; y es que de eso se trata: de poner de manifiesto cómo Pilatos (al igual que Judas) está elegido para el mal y lleva a cabo crímenes que no podrá castigar la justicia humana, sino tan solo la divina. Así pues, reconociendo claramente su condición de apócrifa, la leyenda no por ello pierde interés, sino más bien al contrario y, además, se ajusta a la finalidad didáctica. ${ }^{14}$

I4. Esta leyenda es un buen ejemplo de cómo el predicador puede utilizar y seleccionar el material hagiográfico en 
El mero hecho de poner el foco narrativo en el personaje malvado, de otorgarle un espacio dentro del legendario junto a las figuras de santidad, le confiere un protagonismo, una condición de héroe que quizá resulta estimulante para unos fieles a quienes no se están contando ahora las virtudes, sufrimientos y valentías de los mártires, sino el curriculum de crímenes que protagoniza el gobernador antes de acabar su existencia de la peor forma posible y ser entregado a un castigo eterno.

Como en el caso de la leyenda de Judas, la leyenda queda perfectamente delimitada con dos etiquetas que la califican de apocrypha, que son las que recogemos aquí:

$L A \S$ I83-185: Et quia Christum in mortem tradiderunt Iudas per auaritiam, Iudei per inuidiam, Pylatus per timorem, ideo uidendum esset de pena a deo hiis inflicta merito huius peccati; 184sed de pena et origine Iude inuenies in legenda sancti Mathie, de pena et excidio Iudeorum in legenda sancti Iacobi minoris. I85De pena autem et origine Pylati in quadam hystoria licet apocrypha sic legitur:

$[\ldots]$

$L A \S 256-257$ : Hucusque in predicta hystoria apocrypha legitur. 257Que utrum recitanda sit lectoris iudicio relinquatur

La primera de ellas está recogida en Vlat y Elat, mientras que la segunda no está recogida en ninguno de estos dos manuscritos representativos de $L A 1$.

Si nos fijamos en los pasajes correspondientes de los manuscritos catalanes, vemos que en este caso no coinciden con las lecturas de $L A$. Todos los manuscritos recogen este capítulo y también la leyenda de Pilatos, y aluden asimismo a la fuente de la que la leyenda está tomada; pero omiten la primera especificación de 'apócrifa', que sí está en los dos manuscritos representantes de $L A$ y y, al contrario, recogen la advertencia final, que no está en ninguno de los dos:

\begin{tabular}{|l|l|l|l|l|}
\hline$L A$ & $E$ (ff. 74r; 75r) & $V$ (ff. I4Ov; I42v) & $P$ (ff. 87r; 88r) & $B$ (ff. IO3v; IO5r) \\
\hline $\begin{array}{l}\text { I85 De pena autem et origine } \\
\begin{array}{l}\text { Pylati in } \\
\text { quadam hystoria licet } \\
\text { apocrypha sic legitur }\end{array}\end{array}$ & $\begin{array}{l}\text { E de le pene e del } \\
\text { neximent de Pilà } \\
\text { uos conterem are axí } \\
\text { com ho recompta } \\
\text { una ystòria en la } \\
\text { qual se lig axí }\end{array}$ & $\begin{array}{l}\text { E de la pena e } \\
\text { del neximent } \\
\text { de Pilat en una } \\
\text { istoria la qual se } \\
\text { lix en axí }\end{array}$ & $\begin{array}{l}\text { De la pena e } \\
\text { del nexement } \\
\text { de Pilat en Ia } \\
\text { ystòria en la qual } \\
\text { se lig enayxí }\end{array}$ & $\begin{array}{l}\text { De la pena e del } \\
\text { naxement de Pilat en Ia } \\
\text { ystòria en la cal se lig } \\
\text { enayxí }\end{array}$ \\
\hline $\begin{array}{l}\text { 256 Hucusque in predicta } \\
\text { hystoria apocrypha legitur. } \\
\text { 257 Que utrum recitanda sit } \\
\text { lectoris iudicio relinquatur }\end{array}$ & $\begin{array}{l}\text { E moltes d'altres } \\
\text { coses se ligen en la } \\
\text { ystòria qui no són } \\
\text { recomptadores }\end{array}$ & $\begin{array}{l}\text { E moltes d'atres } \\
\text { coses se ligen } \\
\text { en la istòria } \\
\text { que li són } \\
\text { recomptadores, } \\
\text { a albir de legidor } \\
\text { és jaquit }\end{array}$ & $\begin{array}{l}\text { E moltes } \\
\text { d'autres causes } \\
\text { se ligen en } \\
\text { la ystòria; } \\
\text { que si són } \\
\text { recomtadores, a } \\
\text { albire del ligidor } \\
\text { és giquit }\end{array}$ & $\begin{array}{l}\text { E moltes d'autres } \\
\text { causes se ligen en la } \\
\text { Ystòria; que si són } \\
\text { recomtadores, al libre } \\
\text { del ligedor és giquit }\end{array}$ \\
\hline
\end{tabular}

función de su auditorio (vid. Maggioni 200I: 33): "Le esigenze da rispettare qui sono duplici: da una parte del pulpito c'é il predicatore, che, come prescrive Umberto di Romans, deve necesariamente tenere conto delle finalità didattiche e suasorie del suo sermone e non può disinteressarsi completamente della verosimiglianza di quanto dice; dall'altra parte ci sono i fedeli delle chiese e delle piazze, più sensibili all'interessante e a quella meraviglia che scaturisce di fronte ad un intreccio ben congegnato o di fronte ad avvenimenti oltremodo singolari”. 
Cabe observar que el manuscrito $E$ muestra de nuevo una singularidad, ya que reproduce de manera solo aproximada, o incluso podríamos decir que incorrecta, esa advertencia final, que en los otros tres manuscritos $(V P B)$ está recogida de forma fiel al texto latino.

En cualquier caso, lo que resulta evidente es que, frente a los pasajes anteriores en que coincidían con $L A$, en este pasaje los manuscritos catalanes muestran, de manera unánime, un comportamiento diferente, y se alejan de la tradición de $L A$ s por partida doble: omiten una especificación que $L A t$ sí tiene, y presentan otra que $L A 1$ omite y que corresponde a $L A 2$.

Además, ambas discrepancias parecen caminar en direcciones opuestas en lo que respecta al rigor y tolerancia hacia lo apócrifo, en el sentido de que una de ellas presenta de manera más laxa la leyenda de Pilatos, desdibujando su condición de apocrypha, mientras que la otra apunta a una actitud más estricta, al incluir una advertencia que, según Maggioni, fue introducida por Vorágine precisamente en su segunda redacción de la obra $\left(L A_{2}\right)$, en correspondencia con una postura más cauta y prudente ante lo apócrifo. Esta especie de contradicción hace que, en el caso de esta leyenda, los manuscritos catalanes representen, por un lado, un testimonio más tolerante que $L A t$ (tal como la reconstruye Maggioni) y, por el otro, un testimonio más estricto. ${ }^{55}$

\subsection{De sancto Georgio, \$\$ 12-17}

En esta ocasión el término hace referencia a otro tipo de elemento que parece indicar una evolución hacia la prudencia en Vorágine: ahora no es la leyenda de un 'malvado', sino la de un santo, San Jorge, la que es etiquetada como apócrifa, porque ni su martirio ni su lugar de culto están probados: $:^{16}$

$L A \S \S$ I2-I7: Eius legenda inter scripturas apocryphas in Niceno concilio connumeratur ex eo quod eius martyrium certam relationem non habet. I3Nam in kalendario Bede dicitur quod sit passus in Persida in ciuitate Dyospoli; I 4 alibi legitur quod quiescit in ciuitate Dyospoli, que prius Lidda uocabatur et est iuxta Ioppem. I5Alibi quod passus sit sub Diocletiano et Maximiano imperatoribus. I6Alibi quod sub Diocletiano imperatore Persarum presentibus LXX regibus imperii sui. I 7 Hic quod sub Daciano preside imperantibus Diocletiano et Maximiano.

Esta advertencia no está ni en Vlat ni en Elat y, por tanto, es otra de esas aclaraciones que incluyó Vorágine en un momento posterior de la redacción de la obra, correspondiente ya a $L A 2$.

En lo que respecta a los manuscritos catalanes, la primera observación es que la leyenda no está en el manuscrito $E$, pero sí en $V P B$. En estos tres manuscritos se recoge la advertencia de manera unánime, con la interesante observación de que en este caso el adjetivo latino apocryphas, referido a scripturas, no se interpreta como sinónimo de falso, como veíamos en la leyenda de Judas ("no creseguda", vid. supra el apartado 2.2), sino como no confirmado por la ortodoxia ("no provades"), lo cual significa que el traductor catalán percibe diferentes acepciones del término y se preocupa de recogerlas en su traducción. Así pues, los manuscritos catalanes se apartan nuevamente de $L A \uparrow$ y, como en el caso de la advertencia final de la leyenda de Pilatos, parecen acercarse a $L A 2$ al

I5. Ello corrobora la premisa que formulábamos anteriormente (vid. supra n. 3) en el sentido de que no podríamos interpretar esas diferencias como resultado de una intervención consciente del traductor catalán que hubiera podido querer modificar o alterar las menciones de 'lo apócrifo' de su modelo latino.

I6. Vorágine, siguiendo a Humberto de Romans, afirma que la leyenda fue incluida entre las apócrifas en el Concilio de Nicea, pero en realidad fue el decreto pseudogelasiano del s. VI (vid. Boureau ed. 2004: i2o9; Maggioni ed. 2007: I542). 
incluir este aviso sobre la leyenda del santo que Vorágine no había considerado necesario incluir en versiones más tempranas de la obra:

\begin{tabular}{|c|c|c|c|c|}
\hline$L A$ & $E$ & $V$ (f. I6ov) & $P($ f. $97 \mathrm{r})$ & $B$ (f. пा $6 \mathrm{r})$ \\
\hline $\begin{array}{l}\text { I2Eius legenda inter scripturas } \\
\text { apocryphas in Niceno concilio } \\
\text { connumeratur ex eo quod eius } \\
\text { martyrium certam relationem } \\
\text { non habet. I3Nam in kalendario } \\
\text { Bede dicitur quod sit passus } \\
\text { in Persida in ciuitate Dyospoli; } \\
\text { I } 4 \text { alibi legitur quod quiescit in } \\
\text { ciuitate Dyospoli, que prius } \\
\text { Lidda uocabatur et est iuxta } \\
\text { Ioppem. I5Alibi quod passus sit } \\
\text { sub Diocletiano et Maximiano } \\
\text { imperatoribus. I6Alibi quod sub } \\
\text { Diocletiano imperatore } \\
\text { Persarum presentibus LXX } \\
\text { regibus imperii sui. I7Hic } \\
\text { quod sub Daciano preside } \\
\text { imperantibus } \\
\text { Diocletiano et Maximiano. }\end{array}$ & & $\begin{array}{l}\text { La sua ligenda és } \\
\text { atrobadar7 entre } \\
\text { les scriptures no } \\
\text { provades, per ço } \\
\text { com no fo cert del } \\
\text { seu martiri; cor } \\
\text { en lo colendor de } \\
\text { Beda és dit que } \\
\text { ell sofferí passió } \\
\text { per en Pèrcia en } \\
\text { la ciutat de Espoli, } \\
\text { qui avia nom } \\
\text { Lida, e és coste } \\
\text { Ope. En altra } \\
\text { loch se lig que } \\
\text { ell sofferí passió } \\
\text { per en Dioclecià } \\
\text { e per en Maximià } \\
\text { emperadors. En } \\
\text { altra loch se lig } \\
\text { que ell sofferí } \\
\text { passió sots en } \\
\text { Dioclesian, } \\
\text { emperador de } \\
\text { Pèrsia e de LXX } \\
\text { reys dels seu } \\
\text { inperi. }\end{array}$ & $\begin{array}{l}\text { La sua legenda } \\
\text { és atrobada entre } \\
\text { les escriptures no } \\
\text { provades, per so } \\
\text { car no fo cert del } \\
\text { seu martiri. Car en } \\
\text { lo Kalender d'en } \\
\text { Beda és dit que él } \\
\text { soferí passió en } \\
\text { Pèrsia en la ciutat } \\
\text { Deyspoli que avia } \\
\text { nom Lida e és } \\
\text { costa Opem. En } \\
\text { autre loc se lig } \\
\text { qu'él soferí pasion } \\
\text { per en Dioclecian } \\
\text { e·n Maximian, } \\
\text { emperadors; e·n } \\
\text { altre loc se lig que } \\
\text { él soferí pasion } \\
\text { sotz Dioclecian, } \\
\text { emperador } \\
\text { de Pèrsia, en } \\
\text { presència de LXX } \\
\text { reys del seu enperi. }\end{array}$ & $\begin{array}{l}\text { La seua ligenda és } \\
\text { atrobada entre les } \\
\text { scriptures no provades, } \\
\text { per so car no fo cert } \\
\text { del seu martiri. Car en } \\
\text { lo Calender d'en Beda } \\
\text { és dit que ell sofferí } \\
\text { passió en Pèrsia en la } \\
\text { ciutat Diospoli. E en } \\
\text { altre loch és lest que } \\
\text { ell es pausà en la ciutat } \\
\text { de Dispoli que avia } \\
\text { nom Lida que és costa } \\
\text { Opem. E en autre loch } \\
\text { se lig que soferí passion } \\
\text { per en Dioclecian e en } \\
\text { Maximian, emperadors. } \\
\text { E en altre loch se lig que } \\
\text { él sofferí pasion sots en } \\
\text { Dioclecian, emperador } \\
\text { de Pèrsia, en presència } \\
\text { de LXX reys del seu } \\
\text { emperi }\end{array}$ \\
\hline
\end{tabular}

\subsection{De sancto Iacobo apostolo, \$\$ 93; $143 ; 156$}

En el marco de la vida del apóstol Santiago, Vorágine recurre nuevamente a esa fuente que denomina Hystoria apocrypha para explicar la toma de Jerusalén por parte de Vespasiano y Tito como un castigo al pueblo judío, responsable también de la muerte de Cristo y, por ello, otro enemigo del cristianismo como Judas o Pilatos. De acuerdo con esta explicación, un tal Albano, que se dirigía a Roma como enviado de Pilatos para presentarse ante Tiberio y excusar a aquél por la muerte de Jesús, es desviado de su ruta por una tormenta y llega a Galacia, donde gobierna Vespasiano. Este, informado por Albano del poder de Jesús y milagrosamente curado de una dolencia que sufría desde la infancia solo por creer en ese poder, decide emprender una expedición militar contra Jerusalén y los judíos, por haber provocado la muerte de Jesús. ${ }^{18}$

Más adelante, tomado de esa misma fuente, reproduce el episodio de la enfermedad de Tito, quien, trastornado por la alegría y la excitación al conocer la noticia de que su padre ha sido convertido en emperador, resulta afectado por una parálisis de la que será curado mediante un

I7. El texto del manuscrito dice, en realidad, "és provade", pero el editor, considerándolo un error posiblemente por el "provades" siguiente, lo sustituye por "és atrobada”, siguiendo la lectura de PB (vid. Rebull ed. r976: 224).

I8. Este relato forma parte del ciclo apócrifo en torno a la figura de Pilatos. Sobre el tema vid. Izydorczyk I997; Boureau 2004: II97-98; Gounelle 2OII; Baudoin 2OI2; Gounelle 2013. 
singular procedimiento. Al final del episodio, y tal como hemos visto en el caso de la leyenda de Judas y en la leyenda de Pilatos, Vorágine introduce nuevamente la advertencia ya conocida sobre las cautelas con las que conviene decidir si debe o no ser recitada.

Así pues, en este capítulo son tres las menciones que encontramos del término:

$L A \S 93$ : Hec autem fuit causa aduentus ipsorum in Iherusalem, sicut in quadam hystoria inuenitur, licet apocrypha.

$[\ldots]$

$L A$ § I43: Titus autem, ut in eadem hystoria apocrypha legitur, audiens patrem suum in imperium sublimatum, tanto gaudio et exultatione repletur quod neruorum contractione ex frigiditate corripitur et altero crure debilitatus paralysi torquetur.

$[\ldots]$

$L A \S$ I56: Vtrum autem hec hystoria apocrypha narranda sit, lectoris iudicio relinquatur.

De ellas, las dos primeras aparecen en Elat pero no en Vlat. Es decir, por primera vez encontramos una discrepancia entre los dos manuscritos elegidos por Maggioni como representantes de $L A$, ya que tanto la primera especificación de 'apócrifa' para la fuente (§ 93) como la segunda mención a propósito del episodio de la enfermedad de Tito (§ I 43), aparecen solo en Elat, y no en Vlat.

La advertencia final ( $§ I_{5}^{6}$ ), en cambio, falta en los dos manuscritos, al igual que en los casos anteriores de la leyenda de Judas y de Pilatos.

En lo que respecta a los manuscritos catalanes, la vida de Santiago no está en el manuscrito $E$ (igual que hemos visto en el caso de la leyenda de San Jorge), pero sí en VPB. Estos tres manuscritos siguen la lectura de Vlat en el primer caso: se menciona la fuente, pero sin la etiqueta de apócrifa.

En el pasaje siguiente, apartándose de la tradición latina, los tres manuscritos coinciden en omitir el episodio de la enfermedad y curación de Tito y, por tanto, no recogen tampoco la mención de la fuente de la que la noticia está tomada.

Por último, la advertencia final, omitida al igual que ocurre en las leyendas de Pilatos y Judas tanto en Vlat como en Elat, tampoco aparece en los manuscritos catalanes:

\begin{tabular}{|c|c|c|c|c|}
\hline$L A$ & $E$ & $V$ (f. I $\left.73^{r}\right)$ & $P($ f. IOجv $)$ & $B$ (f. I2 $7 \mathrm{r})$ \\
\hline $\begin{array}{l}\text { 93 Hec autem fuit causa aduentus ipsorum } \\
\text { in Iherusalem, sicut in quadam hystoria } \\
\text { inuenitur, licet apocrypha. }\end{array}$ & - & $\begin{array}{l}\text { E fo asò cosa de } \\
\text { lur aveniment, } \\
\text { segons que } \\
\text { trobam en una } \\
\text { istòria }\end{array}$ & $\begin{array}{l}\text { E fo aysò } \\
\text { causa de lur } \\
\text { aveniment en } \\
\text { Jherusalem, } \\
\text { segons que·s } \\
\text { troba en una } \\
\text { ystòria }\end{array}$ & $\begin{array}{l}\text { E fo aysò causa de } \\
\text { lur aveniment en } \\
\text { Jherusalem, segons } \\
\text { que·s troba en una } \\
\text { ystòria }\end{array}$ \\
\hline $\begin{array}{l}{ }_{\text {I} 33 \text { Titus autem, ut in eadem hystoria }} \\
\text { apocrypha legitur, audiens patrem suum } \\
\text { in imperium sublimatum, tanto gaudio } \\
\text { et exultatione repletur quod neruorum } \\
\text { contractione ex frigiditate corripitur et } \\
\text { altero crure debilitatus paralysi torquetur. }\end{array}$ & & - & - & - \\
\hline $\begin{array}{l}{ }_{55} 6 \text { Vtrum autem hec hystoria apocrypha } \\
\text { narranda sit, lectoris iudicio relinquatur }\end{array}$ & & - & -- & - \\
\hline
\end{tabular}




\subsection{De inuentione sanctae crucis, $\$ \S 8 ; 11$}

En este capítulo dedicado al hallazgo de la santa cruz, ${ }^{\text {19 }}$ Vorágine ofrece diversas tradiciones sobre su origen y, entre ellas, la que proporciona una fuente 'apócrifa', según la cual el arcángel Miguel le entregó a Seth una rama diciéndole que, cuando esa rama diera fruto, su padre sanaría. Seth regresó y, al encontrar muerto a su padre, la plantó sobre el túmulo y la rama se convirtió en un enorme árbol que duró hasta la época de Salomón. A continuación, Vorágine pone en duda la veracidad de esta tradición, indicando que es una información que no aparece en ninguna fuente fidedigna:

$L A \S \S$ 8-II: In quadam uero hystoria Grecorum licet apocrypha legitur quod angelus de ligno in quo peccauit Adam eidem tradidit dicens quod quando faceret fructum pater sanaretur. 9Qui rediens et patrem mortuum inueniens ipsum ramum super tumulum patris plantauit; Ioqui plantatus in arborem magnam creuit et usque ad Salomonis tempora perdurauit. IIVtrum autem hec uera sint, lectoris iudicio relinquatur, cum in nulla chronica nec hystoria autentica ista legantur. Salomon autem arborem tam pulchram considerans...

Ni la etiqueta de apocrypha para la fuente ni la advertencia sobre el carácter dudoso de la información están recogidas en Vlat y en Elat, lo cual nos confirma, nuevamente, en lo que respecta al texto latino, la teoría de Maggioni de que se trata de advertencias introducidas en $L A 2$.

En lo que respecta a los manuscritos catalanes, lo primero que hay que decir es que $E$ no recoge el pasaje sobre las diversas tradiciones del origen de la santa cruz, de modo que solo podemos contar, como en otros casos anteriores, con el testimonio de VPB. Estos tres manuscritos, por su parte, siguen fielmente esta tradición de $L A 1$, omitiendo también los mismos elementos que omiten Vlat y Elat:

\begin{tabular}{|c|c|c|c|c|}
\hline$L A$ & $E$ & $V$ (f. I75r) & $P$ (f. Iogr) & $B$ (f. $128 \mathrm{v}$ ) \\
\hline $\begin{array}{l}\text { 8In quadam uero hystoria } \\
\text { Grecorum licet apocrypha } \\
\text { legitur quod angelus de ligno } \\
\text { in quo peccauit Adam eidem } \\
\text { tradidit dicens quod quando } \\
\text { faceret fructum pater sanaretur. } \\
\text { Qui rediens et patrem } \\
\text { mortuum inueniens ipsum } \\
\text { ramum super tumulum patris } \\
\text { plantauit; qui plantatus in } \\
\text { arborem magnum creuit et ad } \\
\text { Salomonis tempora perdurauit. } \\
\text { Vtrum autem hec uera sint, } \\
\text { lectoris iudicio relinquatur, } \\
\text { cum in nulla chronica nec } \\
\text { historia autentica ista legantur. } \\
\text { Salomon autem arborem tam } \\
\text { pulchram considerans... }\end{array}$ & & $\begin{array}{l}\text { Lig-se en una altra } \\
\text { istòria dels grechs } \\
\text { que l'àngel li donà } \\
\text { del fust de què peccà } \\
\text { Adam, e dix-li que } \\
\text { quant levaria fruyt } \\
\text { son pare seria sanat. } \\
\text { E quant en Sech se’n } \\
\text { fo tornat, ell trobà } \\
\text { son pare mort; e } \\
\text { plantà l'arbre, e féu- } \\
\text { se aquí molt gran. } \\
\text { Aquí visqué entrò } \\
\text { al temps de Salamó. } \\
\text { E quant Salamó viu } \\
\text { ten bell arbre... }\end{array}$ & \begin{tabular}{|l|} 
E lig-se en una \\
ystòria dels grecs \\
que l’àngel li donà \\
del fust en què \\
peccà Adam, e dix-li \\
que quant levaria \\
fruyt que son pare \\
siria sanat. E quant \\
en Set se’n fo tornat, \\
él atrobà son pare \\
mort, e plantà \\
l'aybre en lo vas de \\
son padre, e fé-sse \\
aquí mot gran aybre, \\
aquí vivent entrò al \\
tems de Salamó. E \\
quant Salamó vesec \\
tan bel arbre...
\end{tabular} & $\begin{array}{l}\text { Lig-se en una ystòria } \\
\text { dels grecs que l'àngel } \\
\text { li donà del fust de què } \\
\text { peccà Adam, e dix-li } \\
\text { que quant livaria fruyt } \\
\text { que son pare seria sanat. } \\
\text { E quant en Set se’n fo } \\
\text { tornat, él atrobà son pare } \\
\text { mort; plantà l'aybre de } \\
\text { sus lo vas de son pare, } \\
\text { e fé-sse aquí mot gran } \\
\text { aybre, e aquí vivent entrò } \\
\text { al temps de Salamó. E } \\
\text { quant Salamó veseg tan } \\
\text { bel aybre... }\end{array}$ \\
\hline
\end{tabular}

19. Sobre este capítulo vid. Maggioni 2OI3. 


\subsection{De sancto Petro apostolo, $\$$ 212; 224; 243}

En este capítulo tenemos la cuarta y última referencia a la Historia apocrypha como fuente, y esta vez es para hablar del emperador Nerón, el cuarto 'malvado' del cristianismo, junto a Judas, Pilatos y el pueblo judío, a los que ya hemos hecho referencia anteriormente.

También le parece oportuno al dominico detenerse en algunos crímenes del emperador Nerón y, a continuación, relata algunos episodios sobre su leyenda más negra, en relación con su preceptor Séneca y con su madre, así como su extravagante y enfermizo deseo de saber qué se siente en un embarazo y un parto.

En el relato, Vorágine alude dos veces a la fuente de la que toma toda esta información: la primera, a propósito de su cruel actuación en relación con Séneca, al que fuerza al suicidio, y, la segunda, a propósito de su macabra orden de matar a su madre y abrir sus entrañas para inspeccionar el útero donde él mismo había estado.

Después, ya al final de la narración sobre Nerón, Vorágine afirma que eso que ha narrado son datos falsos que no se encuentran en las crónicas:

$L A \S$ 2II- 2I2: Quorum scelerum aliqua hic breuiter inseramus. 2I2Cum Seneca magister suus, ut in quadam hystoria licet apocrypha legitur, condignam mercedem laboris sui speraret, iussit Nero ipsum eligere in cuius arboris ramo suspendium affectaret, dicens quod hoc laboris sui premium ab eo recepturus esset.

$[\ldots]$

$L A \S 224$ : Rursus Nero nefaria mentis ductus uesania, ut in eadem hystoria apocrypha reperitur, matrem occidi et scindi iussit ut uideret qualiter in eius utero fouebatur.

$[\ldots]$

$L A \S 243:$ Hec autem in chronicis non leguntur, sed apocrypha sunt.

De las tres menciones del término, la primera (§ 2I2), referida a la fuente del episodio de Séneca, aparece en Vlat y en Elat. La segunda (\$224), referida a esa misma fuente a propósito de la madre de Nerón, no aparece en Vlat, pero sí en Elat. Tenemos, pues, otro caso de discrepancia entre los dos manuscritos representativos de $L A$ q que vuelve a confirmar que, dentro de $L A$, Vlat es más laxo que Elat y omite advertencias que sí están en Elat. Finalmente, la tercera mención (§ 243), concisa y taxativa, referida a todo lo que se ha narrado sobre Nerón, está omitida en ambos manuscritos, lo que corrobora la teoría de Maggioni de que, al igual que las otras tres advertencias sobre el material tomado de la Hystoria apocrypha, corresponde a LA2.

Veamos cómo se recoge todo esto en los manuscritos catalanes:

\begin{tabular}{|c|c|c|c|c|}
\hline$L A$ & $E\left(\right.$ f. $\left.\operatorname{IO}^{2} ; \mathrm{r}\right)$ & $V($ ff. $206 \mathrm{v} ; 2 \mathrm{O} 7 \mathrm{r}$ ) & $P$ (f. I32v) & $B$ (f. I57v) \\
\hline $\begin{array}{l}{ }_{212} \text { Cum Seneca magister } \\
\text { suus, ut in quadam } \\
\text { hystoria licet apocrypha } \\
\text { legitur, condignam } \\
\text { mercedem laboris } \\
\text { sui speraret, iussit } \\
\text { Nero ipsum eligere } \\
\text { in cuius arboris ramo } \\
\text { suspendium affectaret, } \\
\text { dicens quod hoc laboris } \\
\text { sui premium ab eo } \\
\text { recepturus esset. }\end{array}$ & $\begin{array}{l}\text { Axí com en Senecha, } \\
\text { son maestre, devie } \\
\text { reebre guardó } \\
\text { del seu trabayll, } \\
\text { en Neró li dix: } \\
\text { “Domana en } \\
\text { qual ram d'arbre } \\
\text { volia ésser penyat”. } \\
\text { E que fos a sa } \\
\text { coneguda dient que } \\
\text { aytal guardó } \\
\text { reebria del seu } \\
\text { trabayl }\end{array}$ & $\begin{array}{l}\text { Axí co en Sànecha, } \\
\text { son maestra, devia } \\
\text { reebra guardó del } \\
\text { seu treball, en Neró } \\
\text { li demanà en } \\
\text { qual ram d'arbre } \\
\text { volia ésser penjat } \\
\text { e que fos a sa } \\
\text { coneguda dient que } \\
\text { aytal guardó } \\
\text { reebria del seu } \\
\text { treball }\end{array}$ & $\begin{array}{l}\text { Ayxí co en Sèneca, } \\
\text { son masestre, li } \\
\text { demanés lo gasardó } \\
\text { del seu trebal, en } \\
\text { Neró li manà que } \\
\text { elegés en qual ram } \\
\text { d'aybre volia ésser } \\
\text { penyat, disent que } \\
\text { él aytal gasardó } \\
\text { resebria del seu } \\
\text { trebal. }\end{array}$ & $\begin{array}{l}\text { Ayxí co en Senecha, } \\
\text { so masestre, demà } \\
\text { resebre gardó del } \\
\text { seu trebal, en Neró } \\
\text { li manà que elegís en } \\
\text { qual ram d'aybre volia } \\
\text { ésser penyat, disent } \\
\text { que él aytal gasardó } \\
\text { resebria del seu } \\
\text { trebayl. }\end{array}$ \\
\hline
\end{tabular}




\begin{tabular}{|l|l|l|l|l|}
\hline $\begin{array}{l}{ }_{22} \text { Rursus Nero nefaria } \\
\text { mentis ductus uesania, } \\
\text { ut in eadem hystoria } \\
\text { apocrypha reperitur, } \\
\text { matrem occidi et scindi } \\
\begin{array}{l}\text { iussit ut uideret qualiter } \\
\text { in eius utero fouebatur. }\end{array}\end{array}$ & $\begin{array}{l}\text { Enaprés en Neró } \\
\text { ocís la sua mare, per } \\
\text { ço que vis en qual } \\
\text { manera avia estat en } \\
\text { lo ventre de la mare } \\
\text { sua. }\end{array}$ & $\begin{array}{l}\text { En aprés en Neró } \\
\text { hocís la sua mare, } \\
\text { per ço que vis en } \\
\text { qual manera avia } \\
\text { estat en lo ventra de } \\
\text { la mare sua. }\end{array}$ & $\begin{array}{l}\text { En Neró enaprés } \\
\text { aucís la sua mare, } \\
\text { per so que vesés } \\
\text { en qual manera } \\
\text { avi’estat en lo } \\
\text { ventre de la mare. }\end{array}$ & $\begin{array}{l}\text { Enaprés en Neró aucí } \\
\text { la seua mare, per so } \\
\text { que vasés en qual } \\
\text { manera havia stat en } \\
\text { lo ventre de sa mare. }\end{array}$ \\
\hline $\begin{array}{l}243 \text { Hec autem in } \\
\text { chronicis non leguntur, } \\
\text { sed apocrypha sunt. }\end{array}$ & --------- & --- \\
\hline
\end{tabular}

Como vemos, tanto la leyenda como los episodios que dan lugar a estas advertencias sobre su naturaleza apócrifa están recogidos en todos los manuscritos. Los cuatro coinciden en omitir la primera mención de apócrifa referida a la fuente (\$ 2I2) que, como hemos dicho, sí está en Vlat y Elat. Así pues, discrepan de $L A$ 1, pero no, como hemos visto antes en algunos casos, para incluir una advertencia que no está en esa redacción y sí en $L A 2$, sino para omitirla.

En cuanto a la segunda mención ( $\$ 224$ ), no aparece en ninguno de los cuatro manuscritos, de modo que en este pasaje coinciden con Vlat, que también la omite, frente a Elat, que sí la recoge.

Finalmente, la última reflexión sobre la naturaleza apócrifa de todo lo narrado sobre Nerón (§ 243), que faltaba en Vlat y Elat, no está tampoco en los manuscritos catalanes.

En esta leyenda, por tanto, la tradición catalana no recoge ninguna advertencia sobre lo apócrifo, sea coincidiendo en esta omisión con Vlat y Elat o con Vlat solamente, sea no coincidiendo con ninguno de los dos.

\subsection{De sancta Margarita, $\$ \$ 32-35$}

El elemento apócrifo en este capítulo es un episodio novelesco relacionado con una figura femenina de santidad: Margarita de Antioquía. Ella, que es una hermosa joven, se niega a aceptar los requerimientos amorosos del prefecto y también a adorar a los dioses paganos, por lo que es sometida a tormentos y encerrada en prisión. Cuando se encuentra en la cárcel y le pide a Dios que le muestre a su enemigo, aparece un dragón que representa, naturalmente, el mal, y se abalanza contra la santa; cuando ella le hace la señal de la cruz, el dragón desaparece. Es en este punto cuando Vorágine introduce otra versión, tomada de una fuente que no especifica (ut alibi legitur): el dragón llega a engullir a la santa y es desde su interior desde donde ella hace la señal de la cruz: el dragón revienta y la santa sale sin daño. A continuación, el propio Vorágine censura en cierto modo el episodio y advierte de que es falso:

$L A \S 3^{2-35}$ : Vbi dum esset orauit dominum ut inimicum qui secum pugnabat sibi uisibiliter demonstraret. 33Et ecce, draco immanissimus ibidem apparuit. 34Qui dum eam deuoraturus impeteret, signum crucis edidit et ille euanuit, uel, ut alibi legitur, os super caput eius ponens et linguam super calcaneum porrigens ipsam protinus deglutiuit, sed dum eam absorbere uellet, signo crucis se muniuit et ideo draco uirtute crucis crepuit et uirgo illesa exiuit. 35Istud autem quod dicitur de draconis deuoratione et ipsius crepatione, apocryphum et friuolum reputatur.

El pasaje contiene motivos narrativos interesantes, ${ }^{20}$ y también es particularmente significativo desde el punto de vista textual. En ese contraste de versiones que ofrece Vorágine, tanto Vlat como 
Elat omiten la primera versión que resulta más anodina, según la cual el dragón apareció, pero se retiró al ver la señal de la cruz. Al mismo tiempo, ambos manuscritos omiten también la mención de la fuente alternativa de la que Vorágine toma la versión más dramática y novelesca. Es decir, solo ofrecen esta última versión, la más fantástica, como versión única, si bien después añaden la prudente reflexión de que la noticia de que el dragón engulle a la santa es falsa. ${ }^{21}$

Veamos cómo se recoge en los manuscritos catalanes:

\begin{tabular}{|c|c|c|c|c|}
\hline$L A$ & $E$ (ff. IO9v; IIOr) & $V($ f. 2I 4 r $)$ & $P($ f. I37v) & $B$ (f. I6 3 r) \\
\hline $\begin{array}{l}\text { 33Et ecce, draco immanissimus } \\
\text { ibidem apparuit. } 34 \text { Qui dum } \\
\text { eam deuoraturus impeteret, } \\
\text { signum crucis edidit et } \\
\text { ille euanuit, uel, ut alibi legitur, } \\
\text { os super caput eius ponens } \\
\text { et linguam super calcaneum } \\
\text { porrigens ipsam protinus } \\
\text { deglutiuit, sed dum eam } \\
\text { absorbere uellet, signo crucis se } \\
\text { muniuit } \\
\text { et ideo draco uirtute crucis } \\
\text { crepuit et uirgo illesa exiuit. } \\
\text { 35Istud autem quod dicitur } \\
\text { de draconis deuoratione et } \\
\text { ipsius crepatione, apocryphum } \\
\text { et friuolum reputatur }\end{array}$ & $\begin{array}{l}\text { E mantinent lo } \\
\text { drach li aparech, } \\
\text { molt gran, qui } \\
\text { posà la bocha } \\
\text { sobre lo seu cap, } \\
\text { axí que la deglotí, } \\
\text { e axí com él la } \\
\text { surbia, ela·s senyà } \\
\text { del senyal de la } \\
\text { creu, per què lo } \\
\text { drach esclatà per } \\
\text { virtut de le creu } \\
\text { e axí d'él la verge } \\
\text { sens tot mal. }\end{array}$ & $\begin{array}{l}\text { E mantinent lo } \\
\text { drach li aparech, } \\
\text { molt gran, qui } \\
\text { posà la boca sobre } \\
\text { lo seu cap, axí que } \\
\text { la deglotí. E, axí } \\
\text { com ell la sorbia, } \\
\text { ella·s senyà del } \\
\text { senyal de la creu, } \\
\text { per què lo drach } \\
\text { esclatà per virtut } \\
\text { de la creu e axí } \\
\text { d'ell la verge sens } \\
\text { tot mal. }\end{array}$ & $\begin{array}{l}\text { E mantenent lo } \\
\text { drac li aparec, mot } \\
\text { gran, qui pausà la } \\
\text { sua boca sobre·l } \\
\text { seu cap, ayxí que } \\
\text { la glotí. E ayxí } \\
\text { con él la obsorbia, } \\
\text { ela·s seyà del seyal } \\
\text { de la crou, per què, } \\
\text { lo drac crebà, per } \\
\text { vertut de la crou, e } \\
\text { eyxí d'él la verge } \\
\text { ses tot mal. }\end{array}$ & $\begin{array}{l}\text { E mantenent lo } \\
\text { drach li aparech, } \\
\text { molt gran, qui } \\
\text { pausà la seua bocha } \\
\text { sobre·l seu cap, axí } \\
\text { que la deglutí. E axí } \\
\text { co la sorbia, ela·s } \\
\text { senyà del senyal de } \\
\text { la crou, per què lo } \\
\text { drach crebà, per } \\
\text { vertut de la crou, } \\
\text { per lo mig, e exí } \\
\text { d'él la verge sens } \\
\text { tot mal. }\end{array}$ \\
\hline
\end{tabular}

Los cuatro manuscritos recogen la leyenda y también el episodio que nos ocupa. Al igual que Vlat y Elat, omiten la versión anodina y narran solamente la versión más novelesca según la cual la santa llega a ser engullida por el dragón.

Sin embargo, discrepan de ambos manuscritos latinos en el hecho de que omiten la reflexión última sobre el carácter fantasioso y falso de este episodio, con lo que le conceden credibilidad y no ponen en cuestión su validez. Ocurre aquí, pues, lo mismo que veíamos en el apartado anterior (2.7) a propósito del emperador Nerón y su preceptor Séneca: los manuscritos catalanes se alejan de $L A$, pero no porque presenten advertencias que solo están en $L A 2$, sino porque no presentan una que sí está en $L A$.

En este sentido, y como analizaremos con detenimiento en el apartado siguiente, podríamos decir que el texto catalán va más allá que el texto latino, y da carta de naturaleza al episodio sin ningún

parecen especialmente destacables. En primer lugar, el hecho de que la santa llegue a ser engullida por el dragón, que guarda claros paralelismos con Jonás en el interior de la ballena y se puede entender como un descensus ad inferos (vid. Alcoy r986; Boase 20I8; Puche 2020). En segundo lugar, el hecho de que, en su enfrentamiento con el dragón, la propia santa se protege y se salva venciendo al enemigo, y se muestra especialmente poderosa frente al mal. De hecho, más adelante en la leyenda se hablará de los lamentos del diablo que ha de reconocerse vencido por una mujer. En tercer lugar, la muerte del dragón que 'revienta' (crepuit) recuerda la leyenda de Judas, en la que lo mismo le ocurre al cuerpo de Judas una vez que se ahorca: su cuerpo revienta para que su alma culpable no saliera por su boca, la boca que había besado a Cristo. Así pues, este estallido del cuerpo, por su brutalidad y carácter cruento, se hace característico de una maldad que, por así decir, no tiene cabida en el mismo.

2I. Esa es la información contenida en el aparato crítico de la edición de Maggioni de 2007 que coincide con la anterior de I998. Sin embargo, en otro estudio (2008b: I70), el editor italiano atribuye la advertencia Istud...reputatur a "la deuxième rédaction de l'ouvrage", que entendemos como $L A 2$, lo que resultaría contradictorio. Aquí damos prioridad a la información contenida en la edición de 2007 que es, tal como dijimos al principio, sobre la que basamos este trabajo. 
tipo de advertencia o filtro. Además, vuelve a resultar destacable la unanimidad de los manuscritos catalanes.

\subsection{De assumptione beatae uirginis Mariae, $\$ \$ 1 ; 126-130$}

En este capítulo, Vorágine empieza por mencionar la fuente apócrifa de la que toma la información relacionada con la asunción de la Virgen, que es una obra atribuida a San Juan Evangelista. Más adelante, introduce el episodio de las dudas de Tomás y de cómo, para darle prueba fehaciente de que dicha asunción se había producido, se le hace llegar desde el cielo el cinturón con el que el cuerpo de la Virgen había estado ceñido. A continuación, el dominico introduce una disquisición sobre la naturaleza apócrifa del episodio, apoyándose en este caso en la autoridad de San Jerónimo:

$L A \S$ I: Assumptio uirginis Marie qualiter facta sit ex quodam libello apocrypho qui Iohanni euangeliste ascribitur edocetur.

$[\ldots]$

$L A \S$ I26-I30: Thomas autem cum abesset et rediens credere recusaret, subito zonam qua corpus eius precinctum fuerat ab aere recepit illesam ut uel sic intelligeret totaliter fuisse assumpta.i2 ${ }_{2} \mathrm{Hoc}$ autem totum quod predictum est illud apocryphum, de quo ait Ieronimus in epistola siue sermone ad Paulam et Eustochium, esse uidetur: $128^{\circ} \mathrm{Ne}$ forte si uenerit in manibus uestris illud apocryphum de transitu uirginis dubia pro certis recipiatis, ille sane libellus uere apocryphus est censendus, nisi quo ad aliqua fide digna que uidentur a sanctis approbata; I29que sunt nouem, scilicet quod promissa sit et exhibita uirgini omnimoda consolatio, apostolorum omnium congregatio, sine dolore consummatio, sepulture in ualle Iosaphat preparatio, exequialis deuotio, Christi et totius curie celestis obuiatio, Iudeorum persecutio, miraculorum in omni causa condecente coruscatio, in anima simul et corpore assumptio'. I3oPorro multa alia sunt ibi posita potius ad simulationem quam ad ueritatem, ut quod Thomas non affuerit et ueniens dubitauerit et hiis similia que per se patent que sunt relinquenda potius quam asserenda.

En este caso vuelve a producirse una discrepancia entre los dos manuscritos representativos de $L A$ : Vlat omite la calificación de apócrifo para la fuente que le sirve de base (§ I), así como la disquisición que, apoyada en la autoridad de Jerónimo, cuestiona el episodio y deja claro que es falso. Así pues, en Vlat el episodio recibe carta de naturaleza y entra dentro de la leyenda sin cuestionamiento. Elat, en cambio, aplica un criterio más estricto, y califica de apócrifo el libro, a la vez que después aconseja rechazar la supuesta prueba que la Virgen entrega a Tomás.

Veamos cómo se recoge en los manuscritos catalanes:

\begin{tabular}{|c|c|c|c|c|}
\hline$L A$ & $E$ (ff. I42r;I43v) & $V$ (ff. $266 \mathrm{r} ; 269 \mathrm{r}$ ) & $P$ (ff. I72v; I74v) & $B$ (f. 2OIr) \\
\hline $\begin{array}{l}\text { iAssumptio } \\
\text { uirginis Marie qualiter } \\
\text { facta sit ex quodam } \\
\text { libello apocrypho } \\
\text { qui Iohanni euangeliste } \\
\text { ascribitur edocetur. }\end{array}$ & $\begin{array}{l}\text { Lo puyament de } \\
\text { la Verge madona } \\
\text { sancta Maria en lo } \\
\text { cel en qual manera } \\
\text { és fet } \\
\text { e·nsenyat és } \\
\text { per un libre que } \\
\text { féu sent Johan } \\
\text { Evangelista }\end{array}$ & $\begin{array}{l}\text { Lo puyament de la } \\
\text { Verga Maria en lo } \\
\text { cel en qual manera } \\
\text { sia feyt } \\
\text { es ensenyat per } \\
\text { hun libre que } \\
\text { féu sent Johan } \\
\text { Evangelista }\end{array}$ & $\begin{array}{l}\text { Lo puyament de la } \\
\text { Verge Maria en lo } \\
\text { cel en qual manera } \\
\text { sia feyt és enseyat } \\
\text { per un libre que sent } \\
\text { Johan evagelista fé. }\end{array}$ & $\begin{array}{l}\text { Lo puyament de la } \\
\text { Verge Maria en lo cel } \\
\text { en cal manera sia feyt és } \\
\text { enseyat per un libre que } \\
\text { fé Sent Johan evagelista }\end{array}$ \\
\hline
\end{tabular}




\begin{tabular}{|c|c|c|c|c|}
\hline $\begin{array}{l}\text { I26Thomas autem } \\
\text { cum abesset et rediens } \\
\text { credere recusaret, subito } \\
\text { zonam qua corpus eius } \\
\text { precinctum fuerat ab } \\
\text { aere recepit illesam } \\
\text { ut uel sic intelligeret } \\
\text { totaliter fuisse assumpta. } \\
\text { [§§ I27-I3o] } \\
\text { I3IVestimenta autem } \\
\text { ipsius ad consolationem } \\
\text { fidelium dicuntur in } \\
\text { tumulo remansisse, } \\
\text { unde et de quadam parte } \\
\text { ipsarum uestium tale } \\
\text { miraculum contigisse } \\
\text { narratur. }\end{array}$ & $\begin{array}{l}\text { On com sent } \\
\text { Thomàs no fos } \\
\text { aquí present cant } \\
\text { le seboliren, hanc } \\
\text { no volch ne } \\
\text { creure que·ls } \\
\text { altres li } \\
\text { comptassen, per } \\
\text { què soptosament } \\
\text { li vench del cel la } \\
\text { correge ab qui } \\
\text { la sancta verge era } \\
\text { cinyida, per ço } \\
\text { que cresgués que·l } \\
\text { seu cors era puyat } \\
\text { al cel e tot } \\
\text { l'altre vestiment } \\
\text { romàs en lo vas. } \\
\text { D’una partida dels } \\
\text { vestimens és dit } \\
\text { que faeren aytal } \\
\text { miracle. }\end{array}$ & $\begin{array}{l}\text { On con sent } \\
\text { Thomàs no fos } \\
\text { aquí present quant } \\
\text { hom la sabullia, } \\
\text { anch no volch res } \\
\text { creura que } \\
\text { los altres li } \\
\text { comptassen. Per } \\
\text { què soptosament } \\
\text { li vench del çel la } \\
\text { cinta ab què } \\
\text { era çint lo cors de } \\
\text { sancta Maria, per } \\
\text { ço que creegués } \\
\text { que lo seu cors } \\
\text { era pujat sus al } \\
\text { çel. Tot l'altre } \\
\text { vestiment romàs } \\
\text { al vas. } \\
\text { D’una partida dels } \\
\text { vestimens és dit } \\
\text { que faeren aytal } \\
\text { miracle. }\end{array}$ & $\begin{array}{l}\text { On con sent Thomàs } \\
\text { no fos aquí present } \\
\text { quant hom la sebelia, } \\
\text { anc no·n volc res } \\
\text { creure que·ls autres } \\
\text { li comtesen; per } \\
\text { què soptament li } \\
\text { venc del cel la cinta } \\
\text { ab què era cint } \\
\text { lo cors de senta } \\
\text { Maria, per so que } \\
\text { cresegués que·l seu } \\
\text { cors era puyat sus } \\
\text { al cel. E tot l'autre } \\
\text { vestiment romàs al } \\
\text { vas. D’una partida } \\
\text { dels vestiments és } \\
\text { dit que·n feren aytal } \\
\text { miracle. }\end{array}$ & $\begin{array}{l}\text { On co sent Thomàs no } \\
\text { fos aquí present quant } \\
\text { hom la sebelia, anch no } \\
\text { volch res creyre que·ls } \\
\text { altres li comtassen; } \\
\text { per què de continent li } \\
\text { vench del cel la cinta ab } \\
\text { què era cint lo cors de } \\
\text { Senta Maria, per so que } \\
\text { cresegués que.l seu cors } \\
\text { era puyat sus al cel. E tot } \\
\text { l'altre vestiment romàs al } \\
\text { vas. D'una partida dels } \\
\text { vestiments és dit que } \\
\text { faseren aytal miracle. }\end{array}$ \\
\hline
\end{tabular}

Como vemos, los cuatro manuscritos recogen esta leyenda y también el episodio del apóstol Tomás; y, además, ante la discrepancia entre Vlat y Elat, muestran unanimidad en seguir la lectura del primero frente al segundo. Así pues, también ellos omiten la etiqueta de apócrifo para la fuente, así como las advertencias y reflexiones sobre la conveniencia de desechar esa explicación y considerarla falsa. Por tanto, este episodio, al igual que en Vlat, es presentado en los manuscritos catalanes sin ningún tipo de reserva.

\section{IO CLXVI De sancto Clemente, $\$ \$ 15^{2-157}$}

Esta leyenda resulta especialmente interesante porque introduce acerca de la familia de Clemente toda una trama novelesca de separaciones y reencuentros, que es la que se relata en las Recognitiones. ${ }^{22}$

La aparición del término apocryphus tiene que ver con un episodio relacionado con el apóstol Pedro y Simón el mago. Este último, merced a un encantamiento, ha dotado de su apariencia a Faustiniano, el padre de Clemente, y Pedro le pide a Faustiniano que se dirija a Antioquía y, aprovechando que su rostro es, en apariencia, el de Simón el mago, convenza al pueblo de la inocencia de Pedro y desmienta las calumnias que contra él había vertido Simón. En ese punto del relato es cuando se produce la llamada de atención de Vorágine, que advierte que Dios no precisa de mentiras y que de ningún modo hay que creer que el apóstol diera la orden de mentir, y señala el carácter apócrifo de la fuente. No obstante, a continuación se permite una reflexión sobre una posible interpretación de la actuación del apóstol que lo podría eximir de esa intención de incitar a mentir, en cuyo caso el episodio sería ya admisible:

22. Sobre las Recognitiones vid. entre otros, Cullmann I930; Côté 20or; Pouderon 2009 y Bremmer 2OIO. Sobre el motivo de la anagnórisis, vid. Boulhol 1996. 
LA §§ I49-I57: Dixit ergo Petrus Faustiniano: I50"Quoniam quidem Symon magus esse uideris perge Antiochiam et coram omni populo me excusa ac ea que de me dixit Symon ex persona sui

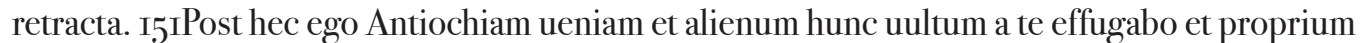
omnibus reddam". $5_{5}{ }_{2} H o c$ tamen nullo modo credendum est quod beatus Petrus mentiri mandauerit, cum deus non indigeat nostro mendacio.I53Ideo itinerarium Clementis in quo hec scripta sunt liber apocryphus est nec ut quibusdam placet suscipiendus in talibus. ${ }_{54} 4$ Verumptamen dici potest quod Petrus si diligenter uerba sua considerentur, non sibi dixit ut Symonem magum esse se diceret, sed ut populo effigiem faciei superinductam ostendens Petrum ex persona Symonis commendaret et mala que dixerat reuocaret. I55Et ille dixit se esse Symonem non quantum ad ueritatem, sed quantum ad apparentiam. I56Vnde quod dixit infra Faustinianus, 'Ego Symon etc.', sic debet accipi, id est ‘quantum ad apparentiam uideor esse Symon’. ${ }_{57}$ Fuit ergo Symon supple putatiuus.

La advertencia sobre la falsedad de la fuente ( $§$ I52-I53) está omitida en Vlat, mientras que sí aparece en Elat, en lo que es un nuevo caso de discrepancia entre los dos manuscritos representativos de $L A$. Después de eso, toda la disquisición sobre la posible interpretación de las palabras del apóstol ( $§ \mathrm{I} 54-\mathrm{I} 57$ ) falta tanto en Vlat como en Elat, y corresponde, por tanto, a la segunda redacción de la obra, cuando Vorágine se preocupa más de matizar a propósito de la cuestión de lo apócrifo.

Veamos cómo se recoge en los manuscritos catalanes:

\begin{tabular}{|c|c|c|c|c|}
\hline$L A$ & $E$ (f. 2 I 3 r) & $V$ (f. I9Ov) & $P$ & $B$ \\
\hline $\begin{array}{l}\text { I49Dixit ergo Petrus } \\
\text { Faustiniano: I50“Quoniam } \\
\text { quidem Symon magus esse } \\
\text { uideris perge Antiochiam et } \\
\text { coram omni populo me excusa } \\
\text { ac ea que de me dixit Symon ex } \\
\text { persona sui retracta. I5IPost } \\
\text { hec ego Antiochiam ueniam } \\
\text { et alienum hunc uultum a te } \\
\text { effugabo et proprium omnibus } \\
\text { reddam”. } \\
\text { [\$ } 5^{2} \text {-I57] } \\
\text { I58Perrexit igitur Faustinianus } \\
\text { pater Clementis Antiochiam }\end{array}$ & $\begin{array}{l}\text { Per què sent Pere dix } \\
\text { a·n Faustinian: “Ve } \\
\text { en Antiotxa per ço } \\
\text { car sembles en Simon } \\
\text { Mach e escuse’m } \\
\text { devant tot lo poble e } \\
\text { digues que no és ver } \\
\text { so que ha dit de mi en } \\
\text { Simon. Aprés assò jo } \\
\text { vendré là e faré devant } \\
\text { tots que tu auràs aytal } \\
\text { care com solies”. Per } \\
\text { què en Faustinian pare } \\
\text { de sent Climent se } \\
\text { n’anà en Antiotxa }\end{array}$ & $\begin{array}{l}\text { Per què sent Pere dix a·n } \\
\text { Faustinià: “Ve an Antiotxa } \\
\text { cor sembles en Simon } \\
\text { Macus; e escusa’m denant } \\
\text { tot lo poble. E digues que } \\
\text { no és ver tot lo que ha dit } \\
\text { de mi Simon. Aprés açó, } \\
\text { venré là, a faré denant } \\
\text { tots que tu·t auràs aytal } \\
\text { care com aver solies”. Per } \\
\text { què Faustinià, pare de } \\
\text { sent Climent, se’n anà an } \\
\text { Antiotxa. }\end{array}$ & - & \\
\hline
\end{tabular}

Debido a una laguna, la leyenda no se conserva en el manuscrito $P .{ }^{23}$ En el manuscrito $B$ sí está la leyenda, pero se omite todo el episodio de Pedro, Simón el Mago y Faustiniano, por lo que no hay lugar para la advertencia sobre el elemento apócrifo. Por otra parte, en $V$ y en $E$ sí está la leyenda y también el episodio, si bien está muy resumido y se omiten muchos pasajes y detalles narrativos presentes en el texto latino. En lo que respecta a nuestro interés particular, que es la mención de lo apócrifo, ambos manuscritos siguen a Vlat, por lo que no solo omiten la interpretación de las

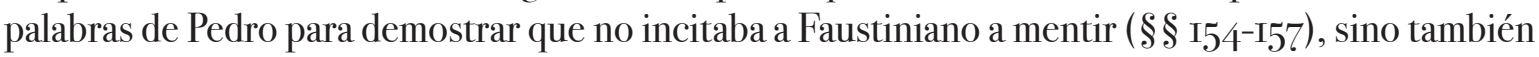
la advertencia sobre la falsedad de la fuente ( $§$ I $\left.5^{2-I} 53\right)$.

Es esta la única ocasión en que encontramos una discrepancia significativa entre los manuscritos catalanes, porque ahora no se trata de que la leyenda esté o no recogida en uno de los manuscritos,

23. El editor la suple a partir del manuscrito B (vid. Coromines ed. I977: 419-424). 
sino que los tres que sí la transmiten $(E V B)$ ofrecen diferentes versiones, de modo que en $B$ el episodio en cuestión no aparece, mientras que en $E$ y $V$ sí está recogido.

\title{
3 Reflexiones sobre los datos: la actitud ante lo apócrifo en la tradición catalana
}

\begin{abstract}
A partir del análisis comparativo que precede, vamos ahora a comprobar si los datos que hemos obtenido nos permiten, de acuerdo con el objetivo que pretendíamos, vincular el posible modelo latino de la traducción catalana con $L A 1$ o con $L A 2$.

Los resultados no son homogéneos, como hemos ido viendo, y para hacer más clara nuestra reflexión, los agrupamos en tres apartados siguiendo una progresión que se aleja cada vez más de una vinculación clara y nítida a $L A$, identificada con los dos manuscritos que Maggioni señala como más representativos de esta redacción, que son Vlat y Elat.
\end{abstract}

\section{I Coincidencias de los manuscritos catalanes con Vlat y con Elat (=LA1)}

De los diez capítulos analizados que contienen una o más veces el término apocryphus, tenemos tres en los que los manuscritos catalanes coinciden plenamente con el testimonio de Vlat y Elat. Los capítulos en cuestión son De sancto Thoma (2.I), De sancto Mathia (2.2) y De inuentione sanctae crucis (2.6).

En ellos, tanto los manuscritos catalanes como los dos manuscritos latinos representantes de LA t omiten las reservas sobre el episodio de la actuación del apóstol Tomás (De sancto Thoma apostolo $§ 33-46$ ). También omiten las dudas sobre la conveniencia de utilizar para la recitación la leyenda de Judas (De sancto Mathia apostolo $\$ § 5^{\mathrm{I}} 5^{2}$ ), tomada de una fuente que etiquetan como apocrypha (\$ I3-I4). Finalmente, tampoco recogen la advertencia sobre el carácter dudoso de una de las tradiciones acerca del origen de la santa cruz (De inuentione sanctae crucis §§ 8; II).

Además, hay también tres pasajes de otros tres capítulos en los que se da la misma circunstancia de que Vlat, Elat y los manuscritos catalanes coinciden, y por eso los citamos en este grupo. ${ }^{24}$ Son los siguientes:

- En De sancto Iacobo apostolo, la advertencia final sobre la cautela en la utilización del contenido apócrifo previamente relatado ( $\$$ I56) está omitida en Vlat y Elat y también en los manuscritos catalanes.

- Lo mismo ocurre en De sancto Petro apostolo con la advertencia final (§ 243), que incluye Vorágine después de la leyenda de Nerón: está omitida en Vlat y Elat y también en los manuscritos catalanes.

- En De sancta Margarita, tanto Vlat y Elat como los manuscritos catalanes omiten la versión más anodina del encuentro del dragón con la santa (§ 34) y recogen solamente la versión más novelesca y maravillosa.

Así pues, de acuerdo con los testimonios pertenecientes a este grupo, podríamos concluir que el modelo latino de la tradición catalana, cuyos manuscritos muestran una gran unanimidad,

24. Sin embargo, en estos capítulos encontramos también pasajes con discrepancias significativas entre la tradición catalana y los dos manuscritos latinos (Vlat y Elat), y por eso los incluimos en el grupo 3.2, o bien en el grupo $3 \cdot 3$. 
pertenece a la tradición de $L A \uparrow$ y, por ello, omite la mayor parte de las advertencias y cautelas sobre el contenido apócrifo que Vorágine incluye en una redacción posterior de la obra, correspondiente a $L A 2$.

Sin embargo, esta conclusión, en principio tan evidente, no es corroborada por otros pasajes donde la comparación ofrece otros resultados. En efecto, hay pasajes en los que el testimonio de Vlat no coincide con el de Elat y esa diferencia nos obliga a introducir matices en la identificación de $L A$ y y cuestionarnos con cuál de los dos coinciden los manuscritos catalanes cuando se produce esa discrepancia.

De acuerdo con nuestro análisis, en caso de discrepancia entre Vlat y Elat, los manuscritos catalanes siempre coinciden con Vlat frente a Elat, y nunca al contrario. Vamos a ver cuáles son esos casos, que son los que recogemos en el siguiente grupo.

\subsection{Coincidencias de los manuscritos catalanes con Vlat, pero no con Elat}

Los capítulos en los que los manuscritos catalanes presentan coincidencias con Vlat contra el testimonio de Elat son De assumptione beatae uirginis Mariae (2.7), De sancto Iacobo apostolo (2.5) y De sancto Clemente (2.IO).

En De assumptione beatae uirginis Mariae los manuscritos catalanes omiten, al igual que Vlat, la calificación de apócrifa para la fuente de referencia (\$ I), así como las reservas acerca de la prueba que supuestamente recibe el apóstol Tomás para hacerle creer (§§ I27-I3O). Estas reservas, apoyadas en el testimonio de San Jerónimo, sí están en Elat.

Por otro lado, la calificación de apocrypha para la fuente de donde se toma la historia del castigo de los judíos (De sancto Iacobo apostolo § 93) aparece en Elat pero no en Vlat ni en los manuscritos catalanes. ${ }^{25}$

En De sancto Clemente, la advertencia de que la fuente de la que está tomado el episodio de Pedro y Simón el Mago y Faustiniano no es de fiar (§§ I52-I53) no está en Vlat (pero sí en Elat) ni en los manuscritos catalanes.

Además, en De sancto Petro apostolo, donde Vorágine incluye la leyenda de Nerón, hay una mención de la fuente apócrifa (\$224) que está omitida en Vlat y también en los manuscritos catalanes, y que, por tanto, se alinea con los testimonios de este apartado. ${ }^{26}$

Si repasamos los pasajes de este grupo, vemos que confirman la tendencia que señalábamos en el anterior, en el sentido de que los manuscritos catalanes siguen siempre la variante más laxa, que ahora no es $L A$ s frente a $L A 2$ sino, dentro de $L A 1$, Vlat frente a Elat. Es muy destacable que no hemos encontrado pasajes donde ocurra lo contrario; es decir, que coincidan con Elat contra Vlat.

Estas discrepancias entre Vlat y Elat ponen en evidencia que la tradición $L A \imath$ no es una realidad homogénea o monolítica y, dado que no hemos constatado ningún caso en que Elat omita una advertencia sobre lo apócrifo que sí esté en Vlat, deducimos que Vlat representa un estadio de la redacción de la obra aún más antiguo que Elat, en el que Vorágine se preocupa aún menos de advertir sobre estos componentes apócrifos. Más allá de esto, de acuerdo con los testimonios de este grupo podríamos mantener la hipótesis de que la tradición catalana deriva de LA y y, particularmente, de un modelo latino más cercano a Vlat que a Elat ya que, en los casos de discrepancia entre ambos, los manuscritos catalanes siempre coinciden con Vlat frente a Elat.

25. En este capítulo hay dos menciones más del término apocryphus: la primera de ellas (§ I 43) no resulta relevante porque aparece en un episodio omitido en la tradición catalana; y la segunda, que es la advertencia final (§ I56), está omitida tanto en Vlat como en Elat, y por eso la hemos incluido en el anterior apartado.

26. Incluimos, no obstante, este capítulo en el apartado siguiente $3 \cdot 3$ (vid. supra n. 24). 
Pero la casuística de nuestro corpus no se agota en los pasajes incluidos en estos dos grupos que acabamos de explicar, ya que también encontramos casos en que los manuscritos catalanes se apartan tanto de Vlat como de Elat en el tratamiento de los elementos apócrifos. Son los que recogemos en el siguiente grupo.

\subsection{Discrepancias de los manuscritos catalanes con Vlat y Elat}

En cuatro capítulos encontramos pasajes en los que los manuscritos catalanes no coinciden con ninguno de los dos manuscritos de $L A \gamma$ en el tratamiento de lo apócrifo. Son los siguientes: De passione Domini (2.3), De sancto Georgio (2.4), De sancto Petro apostolo (2.7) y De sancta Margarita (2.8).

Por un lado, en la leyenda de Pilatos recogida en De passione Domini, los manuscritos catalanes omiten la especificación de apócrifa (§ I85), que sí está en Vlat y en Elat, en alusión a la fuente de la que procede el relato.

También en la leyenda de Nerón, recogida en De sancto Petro apostolo, omiten la mención de la fuente apócrifa que sí está en Vlat y Elat (§ 212).

Además, en De sancta Margarita, aunque coinciden con Vlat y Elat en suprimir la versión más anodina del dragón que se le aparece a la santa (§ 34), como ya vimos, omiten, sin embargo, el juicio sobre el carácter falso del episodio ( $\$ 35$ ) que sí está recogido en Vlat y en Elat.

Por tanto, estas omisiones en los manuscritos catalanes de etiquetas y advertencias que sí están en Vlat y en Elat refuerzan la idea de que la tradición catalana muestra gran tolerancia en relación con la materia apócrifa, y podrían llevarnos a la conclusión de que el modelo latino de la tradición catalana pertenece a $L A$, pero se caracteriza por una actitud más permisiva con lo apócrifo incluso que los dos manuscritos latinos elegidos por Maggioni como representativos de esta redacción.

Sin embargo, hay dos casos que apuntan en la dirección contraria, en el sentido de que encontramos en los manuscritos catalanes dos pasajes sobre lo apócrifo que corresponden a LA2. El primero lo tenemos en De passione Domini donde, después de relatar la leyenda de Pilatos, recogen la advertencia final sobre las reservas para la utilización de la leyenda (\$ $\$ 25-257)$, que no está en ninguno de los dos manuscritos representantes de $L A$ y y que, como hemos visto, según Maggioni fue incluida por Vorágine en una redacción posterior, ya identificada con $L A 2$. El segundo lo tenemos en la advertencia sobre la naturaleza apócrifa, en el sentido de no probada, de la leyenda $D e$ sancto Georgio (§ § I2-I7) que tampoco está en Vlat ni en Elat.

Así pues, estos casos de advertencias sobre lo apócrifo que están en la tradición catalana y corresponden a $L A 2$ ponen en cuestión nuestras conclusiones anteriores y no nos permiten afirmar de forma clara y rotunda que el modelo latino de la tradición catalana pertenece a $L A$.

En realidad, llegados a este punto, nuestra conclusión es que la formulación que hacíamos al principio de nuestro objetivo de trabajo debe ser matizada: más que hablar de vincular el modelo latino de la tradición catalana a $L A \iota$ o bien a $L A 2$, donde la disyuntiva invita a entenderlas como conceptos excluyentes y estancos, es más adecuado hablar de intentar situar el modelo latino de la tradición catalana en un punto determinado dentro de la línea que representa la prevención creciente de Vorágine sobre lo apócrifo; una línea cuyos extremos serían $L A$, como fase o estadio más temprano y laxo (representado quizá por más manuscritos además de Vlat y Elat), y LA2, como fase o estadio más avanzado y estricto.

De acuerdo con el análisis que precede, las coincidencias de la tradición catalana con Vlaty Elat (apartado 3.I) son siempre (excepto en un caso) para omitir etiquetas y advertencias sobre lo apócrifo que sí están en LA2. Por otro lado, todas las coincidencias con Vlat frente a Elat (apartado 3.2) son para omitir advertencias o reflexiones sobre lo apócrifo que sí están en Elat. Y, de los casos 
en que la tradición catalana no coincide con ninguno de los dos (3·3), en tres ocasiones es para omitir advertencias y juicios que están en ambos. Frente a esta mayoría que, dentro de lo exiguo de nuestro corpus, resulta abrumadora, solo los dos pasajes de $3 \cdot 3$ que hemos comentado en último lugar discrepan de Vlat y Elat para incluir advertencias que no están en ninguno de los dos y que sí están en $L A 2$.

Por consiguiente, no podemos establecer esa vinculación nítida del posible modelo latino con $L A$ t tal como la establece Maggioni, pero lo que sí podemos afirmar es que los manuscritos catalanes están mucho más cerca de $L A \imath$ que de $L A 2$ en lo que respecta a las cautelas sobre lo apócrifo, y se caracterizan por una actitud particularmente laxa y tolerante al respecto, en tanto que no recogen la mayor parte de advertencias que serán incluidas en estadios posteriores de la obra latina. Por otro lado, dada la unanimidad que, en general, muestran los cuatro en lo que respecta a estas cautelas y reservas sobre lo apócrifo, no podemos afirmar que unos manuscritos sean más 'estrictos' que otros y, de hecho, ya en varios momentos nos hemos permitido hablar de 'tradición catalana' sin establecer diferencias entre ellos.

Al margen de las incógnitas aún por despejar sobre su posible modelo latino (o quizá modelos), en la Legenda aurea catalana, en tanto que reescritura de la obra latina, ${ }^{27}$ el límite entre lo ortodoxo y lo apócrifo queda bastante desdibujado y el público al que va dirigida recibe con muy pocos filtros esos elementos apócrifos, muchas veces deliciosamente atractivos por su carácter novelesco, en esa combinación, tan característica del género hagiográfico, de docere y delectare. 


\section{Obras citadas}

Albert, Sophie; Puche López, Maria Carmen. 20r9. 'Chambres d'échos d'un nom, Pilate: Oralité et écriture dans trois versions apocryphes vernaculaires de la vie de Pilate’, Estudos de Religião, 33, 3: 73-90 <https://doi.org/IO.I5603/2I76-IO78/er.v33n3p73-90 >

Alcoy i Pedrós, Rosa. 1986. 'El descensus ad inferos de Santa Margarita', D'Art, I2: I27-57 <https:// www.raco.cat/index.php/Dart/article/view/IOoO37>

Avenoza, Gemma; Garcia Sempere, Marinela. 2012. 'Santos y santas en la tradición escrita catalana medieval', in De lo humano y lo divino en la literatura medieval: santos, ángeles y demonios, ed. by Juan Paredes (Granada: Universidad de Granada), pp. 47-6o < $\underline{\text { https://tinyurl.com/y2e2k2kk }>}$

Baños Vallejo, Fernando. 2020 “"Lanzarían grandes carcajadas”: lo apócrifo del Flos sanctorum y la burla de los protestantes', Rilce, 36, 2: 428-52 $\langle$ https://doi.org/IO.I558I/Oo8.36.2.428-52>

Baudoin, Anne-Catherine. 20I2. Ponce Pilate: la construction d'une figure dans la littérature patristique et apocryphe (Paris: EPHE)

Boase, Roger. 20I8. 'The Lady Half-Devoured by a Dragon and the Iconography of St Margaret of Antioch: Interpreting an Anonymous Invención in the Cancionero general (IICG-5I7)', Magnificat Cultura iLiteratura Medievals, 5: I-I7 $<$ https://doi.org/IO.7203/MCLM.5.IO3833 $>$

Boulhol, Pascal. 1996. Anagnorismos: La Scène de reconnaissance dans l'hagiographie antique et médiévale (Aix-en-Provence: Université de Provence)

Boureau, Alain (ed.). 2004. Jacques de Voragine, La Légende dorée, (Paris: Gallimard)

Bremmer, Jan. N. (ed.). 20Io. The PseudoClementines (Leuven: Peeters)

Brunel, Geneviève. I976. 'Vida de Sant Frances: Versions en langue d'oc et en catalan de la Legenda aurea: Essai de classement des manuscrits', Revue d'Histoire des Textes, 6: 219-65<https://doi. org/IO.3406/rht.I978.II5O >

Brunel, Geneviève. 1986. 'Les Saints franciscains dans les versions en langue d'oc et en catalan de la Legenda aurea', in 'Legenda aurea': Sept siècles de difusión: Texte latin et branches vernaculaires, ed. by Brenda Dunn-Lardeau (Montréal: Éditions Bellarmin), pp. IO3-I5

Càmara Sempere, Hèctor. 20I3. 'Flos sanctorum' romançat: edició crítica dels dos incunables Catalans de la 'Legenda aurea' de Jacobus de Voragine (Universitat d'Alacant: unpublished Ph.D. dissertation) $<\underline{\text { http: } / / \text { hdl.handle.net/IOO45/7485I }>}$

Coromines, Joan; Maneikis Kniazzeh, Charlotte. S.; Neugaard, Edward. J. (eds.). r977. Vides de sants rosselloneses, 3 vols (Barcelona: Fundació Salvador Vives Casajuana)

Côté, Dominique. 200I. Le Thème de l'opposition entre Pierre et Simon dans les 'PseudoClémentines'(Paris: Institut d'Études Augustiniennes)

Cullmann, Oscar. 1930. 'Le Problème littéraire et historique du roman pseudoclémentin: Étude sur le rapport entre le gnosticisme et le judéo-christianisme', Revue d'Histoire et de Philosophie religieuses, I0.4-5: 47 I-76 <https://doi.org/IO.3406/rhpr.I930.2783 >

Dunn-Lardeau, Brenda (ed.). r986. 'Legenda aurea': Sept siècles de diffusion: Texte latin et branches vernaculaires (Montréal: Éditions Bellarmin) 
Elizondo, Jose María de. I9ıо. 'La leyenda de San Francisco según la versión catalana del Flos sanctorum: fragmentos y notas', Revista de Estudios Franciscanos, núm. extraordinari abril-maig: 235-6o $<$ https://tinyurl.com/y5wl/w69 $>$

Fleith, Barbara. I990. 'Legenda aurea: Destination, utilisateurs, propagation: L'histoire de la diffusion du légendier au xiiie et au début du xive siècle’, in Raccolte divite di santi dal xï̈ al xviii secolo, ed. by S. Boesch Gaiano (Fasano di Brindisi: Schena), pp. 4I-48

Fleith, Barbara. I99I. Studien zur Überlieferungsgeschichte der lateinischen 'Legenda aurea' (Bruxelles: Société des Bollandistes)

Gaiffier, Baudouin de. 1973. 'L'Historia apocrypha dans la Légénde dorée', Analecta Bollandiana, 9I: $263_{-72}<\underline{\text { https://doi.org/IO.I484/J.ABOL.4.OI263 }>}$

Garcia Sempere, Marinela. 2OI2. 'Vides de sants en català conservades en manuscrits solts i en impresos anteriors a I550', in Vides medievals de sants: difusió, tradició i llegenda, ed. by Marinela Garcia Sempere and Àngels Llorca Tonda (Alacant: Universitat d'Alacant), pp. I85-2O7

Garcia Sempere, Marinela. 20I5. 'Algunes dades sobre els manuscrits de la versió catalana de la Legenda aurea', Medievalia, I8, 2: I55-78 $<\underline{\text { https://doi.org/IO.5565/rev/medievalia.349 }>}$

Goullet, Monique. 2005. Écriture et réécriture hagiographiques: Essai sur les réécritures de vies de saints dans l'Occident latin médiéval (vï̈e-xïie s.) (Turnhout: Brepols) $<\underline{\text { https://doi. }}$ org/IO.I484/M.HAG-EB.5.IO6042>

Gounelle, Rémi. 1994. 'Sens et usage d'apocryphus dans la Légénde dorée', Apocrypha, 5: I89-2IO $<$ https://doi.org/IO.I484/J.APOCRA.2.3OII77>

Gounelle, Rémi. 20II. 'Les Origines littéraires de la légende de Véronique et de la Sainte Face: la Cura sanitatis Tiberï et la Vindicta Saluatoris', in Sacre impronte e oggetti 'non fatti da mano d'uomo'nelle religioni: Atti del Convegno Internazionale, Torino 2010, ed. by A. Monaci Castagno (Alessandria: Edizioni Dell'Orso), pp. 235-5I

Gounelle, Rémi. 20I3. 'Genèse d'un personnage littéraire: Ponce Pilate dans la littérature apocryphe chrétienne', in Ponce Pilate, ed. by Jean-Marc Vercruysse (Arras: Artois Presses Université), pp. 29-40 $\left\langle\underline{\text { https: //go.uv.es/P4 } 1 \mathrm{~S}_{4} \mathrm{Cly}_{4}>}\right.$

Izydorczyk, Zbigniew S. (ed.) I997. The Medieval Gospel of Nicodemus: Texts, Intertexts and Contexts in Western Europe (Tempe, Az: Medieval \& Renaissance Texts \& Studies)

Le Goff, Jacques. 2OII. À la Recherche du temps sacré: Jacques de Voragine et la 'Légende dorée' (Paris: Perrin)

Mackley, Jude S. 2008. The Legend of St Brendan: A Comparative Study of the Latin and AngloNorman Tradition (Leiden: Brill) <https://doi.org/IO.II63/ej.9789004I66622.i-352>

Maggioni, Giovanni Paolo. I995a. Ricerche sulla composizione e sulla trasmissione della 'Legenda aurea'(Spoleto: Fondazione CISAM)

Maggioni, Giovanni Paolo. 1995b. 'Dalla prima alla seconda redazione della Legenda aurea: particolarità e anomalie nella tradizione manoscritta delle compilazioni medievali', Filologia Mediolatina, 2: 259-78

Maggioni, Giovanni Paolo. r995c. 'Appelli al lettore e definizioni di apocrifo nella Legenda aurea: a margine della leggenda di Giuda Iscariota', Studi Medievali, 36: 24I-53 
Maggioni, Giovanni Paolo. 1998. 'Storie malvagie e vite di santi: Storie apocrife, cattivi e demoni nei leggendari condensati del xiii secolo', in Tra edificazione e piacere della lettura: le vite dei santi in età medievale, ed. by Antonella Degl'Innocenti and Franco Ferrari (Trento: Dipartimento di Scienze Filologiche e Storice), pp. I3I-44 〈https://go.uv.es/FeeqhF5 $>$

Maggioni, Giovanni Paolo (ed.). 1998. Iacopo da Varazze Legenda aurea, 2 vols (Firenze: SISMEL, Edizioni del Galluzzo)

Maggioni, Giovanni Paolo. 200I. 'Le molte Legende auree: modificazioni testuali e itinerari narrativi', in De la Sainteté a l'hagiographie: Genèse et usage de la 'Légende dorée', ed. by Barbara Fleith et Franco Morenzoni (Genève: Droz), pp. I5-40

Maggioni, Giovanni Paolo (ed.). 2007. Iacopo da Varazze Legenda aurea: con le miniature del codice Ambrosiano $C_{240}$ inf. (Firenze: SISMEL Edizioni del Galluzzo)

Maggioni, Giovanni Paolo. 20o8a. 'Redattori imprecisi e autori distratti: mancate correzioni e capitoli fuori posto nel testo originale della Legenda aurea', Filologia Mediolatina, I5: 75-93

Maggioni, Giovanni Paolo. 20o8b. 'La Littérature apocryphe dans la Légende dorée et dans ses sources directes: L'Interprétation d'une chaîne de transmission culturelle', Apocrypha, I9: I468I $<$ https://doi.org/IO.I484/J.APOCR.3.7>

Maggioni, Giovanni Paolo. 2OI2. 'Riletture e riscritture agiografiche del XIII secolo: i leggendari abbreviati', in Vides medievals de sants: difusió, tradició i llegenda, ed. by Marinela Garcia Sempere and Àngels Llorca Tonda (Alacant: Universitat d'Alacant), pp. II-34

Maggioni, Giovanni Paolo. 2OI3. 'Between Hagiography and Preaching: The Holy Cross in the works of lacobus de Voragine', Hagiographica, 20: 187-2I7 <https://go.uv.es/ZqXG3Uh>

Pouderon, Bernard. 2009. 'La novela clementina: presentación de un dossier', Myrtia, 24: I43-63 $\langle\underline{\text { https://tinyurl.com/yztryev7 }>}$

Puche López, Maria Carmen. 20I2. 'La vida de María Magdalena en la 'Legenda aurea’ de Iacobus de Voragine y en Vides de sants rosselloneses: un análisis comparativo', Revista de Filología Románica, 29.I: I65-88 <https://doi.org/IO.5209/rev RFRM.2OI2.V29.nI.38953>

Puche López, Maria Carmen. 20I8. 'La leyenda de Judas Iscariote en la tradición catalana de la Legenda aurea y su modelo latino: algunas reflexiones', Cultura Neolatina, 78.3-4: 2II-38

Puche López, Maria Carmen. 20I9. 'La leyenda de Pilatos en la Legenda aurea de Iacobus de Voragine: estructura narrativa y exemplum a contrario’, Hagiographica, 26: 22I-59 $<\underline{\text { https:// }}$ tinyurl.com/yy4006vm>

Puche López, Maria Carmen. 2020. 'Margarita de Antioquía en la Legenda aurea de Jacobo de la Vorágine: texto latino y tradición catalana', eHumanista/IVITRA, I7?: 2I3-3I $<\underline{\text { https://tinyurl. }}$ $\underline{\mathrm{com} / \text { yyvktzol> }}$

Rebull, Nolasc (ed.). r976. Jaume de Voràgine Llegenda àuria (Olot: Aubert Impr.)

Rousselle, Aline. 1983. 'Paulin de Nole et Sulpice Sévère, hagiographes, et la culture populaire', in Les Saints et les stars: Le Texte hagiographique dans la culture populaire, ed. by Jean-Claude Schmidt (Paris: Beauchesne), pp. 27-43

Steinmeyer, Ernst von. 19I8. 'Die Historia apocrypha der Legenda aurea', Münchener Museum für Philologie des Mittelalters und der Renaissance, 3: $555^{-66}$ 
Tausend, Monika. 1995. Die altokzitanische Version B der 'Legenda aurea': Ms. Paris, Bibl. nat., $n$. acq.fr. 6504 (Tübingen: Niemeyer)

Wittlin, Curt J. 2003. 'Manuscrits i edicions de la Legenda aurea rossellonesa-catalana: una mina de materials per a la lexicologia i dialectologia histórica', in Estudis de Llengua i Literatura Catalanes, 45 (=Miscel-lània Joan Veny, 2) (Barcelona: Publicacions de l'Abadia de Montserrat), pp. $123-45$

Zinelli, Fabio. 2009. 'La Légende dorée catalano-occitane: Étude et édition d'un nouveau fragment de la version occitane A', in L'Occitan, une langue du travail et de la vie quotidienne du xüe au xxie siècle: Les Traductions et les termes techniques en langue d'oc, ed. by Jean-Loup Lemaître and Françoise Vielliard (Ussel: Centre Trobar), pp. 263-350 